\title{
Development of Estimation Force Feedback Torque Control Algorithm for Driver Steering Feel in Vehicle Steer by Wire System: Hardware in the Loop
}

\author{
Sheikh Muhammad Hafiz Fahami, ${ }^{1}$ Hairi Zamzuri, ${ }^{2}$ and Saiful Amri Mazlan ${ }^{2}$ \\ ${ }^{1}$ UTM-Razak School of Engineering and Advanced Technology, Universiti Teknologi Malaysia, Jalan Semarak, \\ 54100 Kuala Lumpur, Malaysia \\ ${ }^{2}$ Vehicle System Engineering I-Kohza, North Wing, MJIIT, Universiti Teknologi Malaysia, Jalan Semarak, \\ 54100 Kuala Lumpur, Malaysia \\ Correspondence should be addressed to Hairi Zamzuri; hairi.kl@utm.my
}

Received 11 November 2014; Revised 10 April 2015; Accepted 30 April 2015

Academic Editor: C. S. Shankar Ram

Copyright (C) 2015 Sheikh Muhammad Hafiz Fahami et al. This is an open access article distributed under the Creative Commons Attribution License, which permits unrestricted use, distribution, and reproduction in any medium, provided the original work is properly cited.

\begin{abstract}
In conventional steering system, a feedback torque is produced from the contact between tire and road surface and its flows through mechanical column shaft directly to driver. This allows the driver to sense the steering feel during driving. However, in steer by wire (SBW) system, the elimination of the mechanical column shaft requires the system to generate the feedback torque which should produce similar performance with conventional steering system. Therefore, this paper proposes a control algorithm to create the force feedback torque for SBW system. The direct current measurement approach is used to estimate torque at the steering wheel and front axle motor as elements to the feedback torque, while, adding the compensation torque for a realistic feedback torque. The gain scheduling with a linear quadratic regulator controller is used to control the feedback torque and to vary a steering feel gain. To investigate the effectiveness of the proposed algorithm, a real-time hardware in the loop (HIL) methodology is developed using Matlab XPC target toolbox. The results show that the proposed algorithm is able to generate the feedback torque similar to EPS steering system. Furthermore, the compensation torque is able to improve the steering feel and stabilize the system.
\end{abstract}

\section{Introduction}

The latest generation of integrated steering system is steer by wire (SBW) system which is also known as independent steering system. It eliminates the need of mechanical column shaft between the steering wheel and the front axle system and was replaced with sensor, actuators, and electronic controller unit (ECU) as shown in Figure 1. The SBW system offers numerous advantages such as large space in cabin [1-3]. While, for vehicle manufacturers, the absence of mechanical column shaft gives maximum freedom interior design and ergonomics thus making it more comfortable for the driver $[4,5]$. Moreover, it reduces the driver impact force from the frontal accident. The SBW system is also potential to enhance the vehicle performance such as maneuverability and stability [1].
There are several characteristics of SBW system [1]. One of the characteristics of a SBW system is feedback torque for driver steering feel, whereby it is the most challenging issue in SBW system $[6,7]$. The function of feedback torque is for driver steering feel and steering wheel returnability when drivers release their hand from the steering wheel [8]. Previous researchers have done several studies on how to create the feedback torque. Based on control parameter of vehicle speed and steering wheel angle, Oh et al. [9] developed a torque map to generate the feedback torque. The generated torque quantity is small at low speed and increased at high speed. Authors proposed to control a gain for each control parameter in order to vary the feedback torque. Authors also claimed that the torque map could give engineers freedom to tune for a real driver steering feel. Kim et al. proposed that 


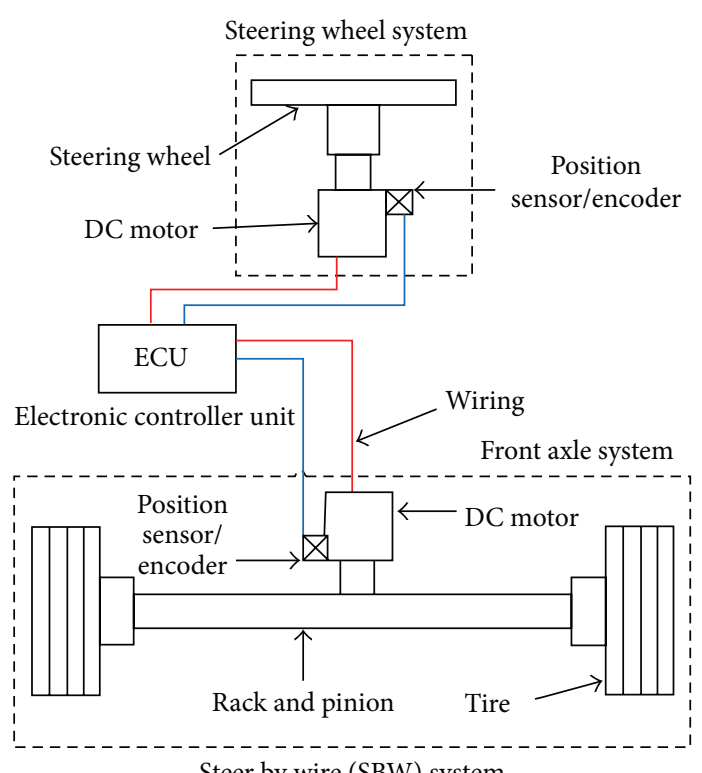

Steer by wire (SBW) system

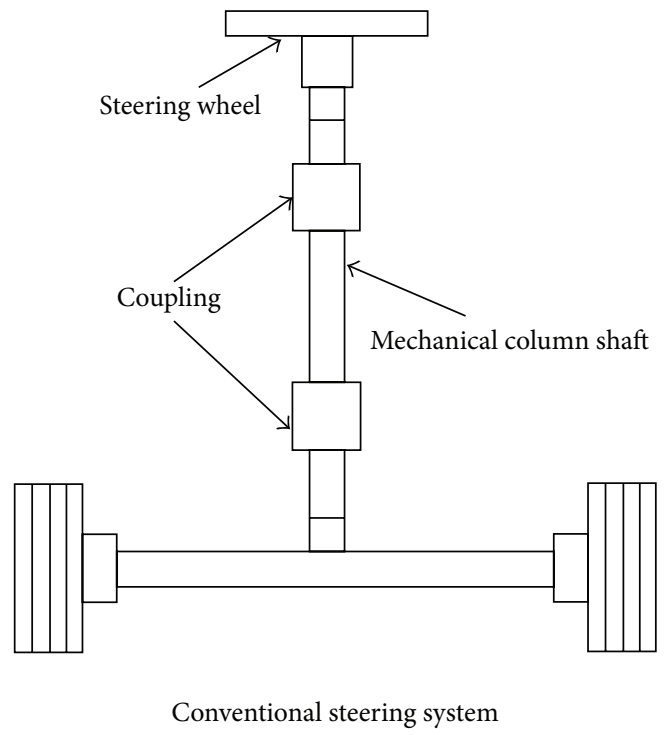

FIGURE 1: Difference between SBW system and conventional steering system.

improvement to the torque map has been made by adding the damping torque to create more realistic driver steering feel and to improve steering wheel returnability [10]. Meanwhile, Amberkare et al. [6], used the steering wheel angle and fed to model transfer function to create a feedback torque. By using the appropriate transfer function, it is possible to change the desired steering feel by varying a proper gain of the transfer function. The approach of the disturbance observer is introduced by Asai et al. [11]. The position and current of the front axle motor are used to generate the feedback torque. Furthermore, a reference model that consists of the inertia and damping factor of steering wheel motor is proposed by Park et al. [12] to generate the feedback torque. The model matching technique which combines the mechanical and electrical parts has been introduced by Odenhtal et al. [13] to generate the feedback torque, while the series of vehicle cornering control algorithm is taken into consideration to optimize the feedback torque as proposed by $\mathrm{Na}$ et al. [14].

The main objective of this paper is to proposes a control algorithm to generate the force feedback torque for driver steering feel in the vehicle SBW system. The subsystem of SBW system which is steering wheel and front axle system is modelled and the control algorithm is explained. To verify the effectiveness of the proposed algorithm, the hardware in the loop (HIL) is presented and interfaced using a Matlab XPC target toolbox. The result was then is compared with electric power steering (EPS) system [15].

\section{The Modelling of Steer by Wire (SBW) System}

The SBW system is divided into two subsystems that consist of steering wheel and front axle system. The system diagram of subsystem is shown in Figure 2.
TABLE 1: Steering wheel system parameter.

\begin{tabular}{llcc}
\hline Parameter & Description & Value & Unit \\
\hline$R_{1}$ & Motor resistance & 5.64 & ohm \\
$L_{1}$ & Motor inductance & 0.017 & henry \\
$K_{s m}$ & Motor constant & 0.024 & $\mathrm{Nm}$ \\
$J_{m 1}$ & Motor inertia & 0.0036 & $\mathrm{kgm}^{2}$ \\
$b_{m 1}$ & Motor damping & 0.0068 & $\mathrm{Nm} /(\mathrm{rad} / \mathrm{s})$ \\
$k_{s 1}$ & Lumped torque stiffness & 0.025 & $\mathrm{Nm}$ \\
$V_{s 1}$ & Voltage source & - & Volt \\
\hline
\end{tabular}

2.1. Steering Wheel Model. The main purpose of steering wheel motor is to generate the steering feedback torque for driver steering feel. Figure 2(a) shows the system diagram for the steering wheel system. The input to the system is the total feedback torque ( $\left.\tau_{\text {total feedback }}\right)$ and the output is the rate change of steering wheel motor angular displacement $\left(\dot{\delta}_{m 1}\right)$, the motor angular displacement $\left(\delta_{m 1}\right)$, and the current of steering wheel motor $\left(i_{a 1}\right)$. The parameters of the steering wheel system are illustrated in Table 1.

The mathematical equations of the steering wheel system are written as follows.

The steering motor angular displacement is

$$
\ddot{\delta}_{m 1}=-\frac{b_{m 1}}{J_{m 1}} \dot{\delta}_{m 1}+\frac{k_{s 1}}{J_{m 1}} i_{a 1}
$$

and the steering motor current is

$$
\dot{i}_{a 1}=-\frac{R_{1}}{L_{1}} i_{a 1}+\frac{k_{s m}}{L_{1}} \dot{\delta}_{m 1}+\frac{V_{s 1}}{L_{1}} .
$$




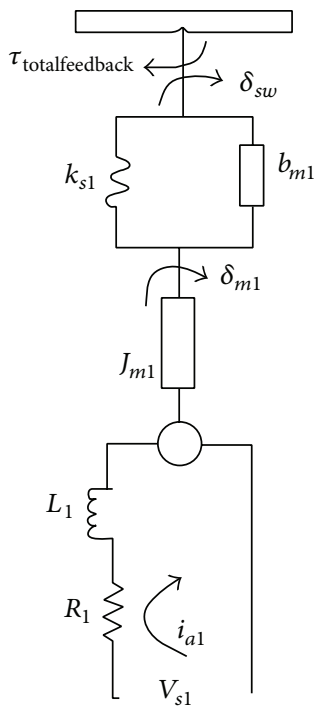

(a)

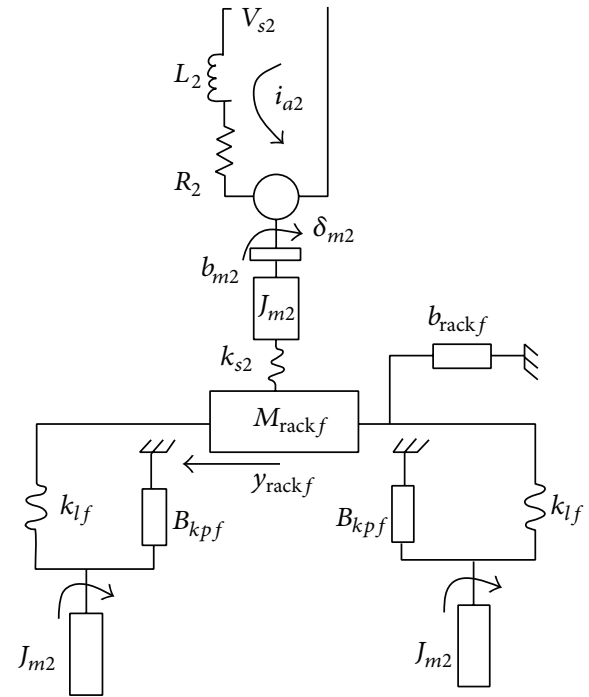

(b)

Figure 2: System diagram: (a) steering wheel and (b) front axle system [15].

Consequently, the state equation of steering wheel system is given as

$$
\begin{aligned}
& \dot{x}_{s m}=A_{s m} x_{s m}+B_{s m} u_{s m}, \\
& y_{s m}=C_{s m} x_{s m}, \\
& x_{s m}=\left[\begin{array}{lll}
\dot{\delta}_{m 1} & \delta_{m 1} & i_{a 1}
\end{array}\right] .
\end{aligned}
$$

And $u_{s m}$ is considered the input of the steering wheel motor and the parameter states are

$$
\begin{aligned}
& A_{s m}=\left[\begin{array}{ccc}
-\left(\frac{b_{m 1}}{J_{m 1}}\right) & 0 & \frac{k_{s 1}}{J_{m 1}} \\
1 & 0 & 0 \\
-\left(\frac{k_{s m}}{L_{1}}\right) & 0 & -\left(\frac{R_{1}}{L_{1}}\right)
\end{array}\right], \\
& B_{s m}=\left[\begin{array}{c}
0 \\
0 \\
\frac{1}{L_{1}}
\end{array}\right], \\
& u_{s m}=\tau_{\text {total feedback }}=V_{s 1} .
\end{aligned}
$$

2.2. Front Wheel System. The function of the front axle system is to ensure the front tire angle follows the steering wheel angle command according to the steering ratio [17]. The front axle is composed of a front axle DC motor, rack and pinion, and tire model. The system diagram of the front axle system and the subsystem block diagram are shown in Figures 2(b) and 3, respectively. The input to the system is the steering wheel angle $\left(\delta_{s w}\right)$, while the front tire angle $\left(\delta_{f}\right)$ is considered the output. The parameters of the front axle system are approximated assumption that are illustrated in Table 2.
TABLE 2: Front axle system parameter [15].

\begin{tabular}{llcc}
\hline Parameter & Description & Value & Unit \\
\hline$R_{2}$ & Motor resistance & 4.64 & $\mathrm{ohm}$ \\
$L_{2}$ & Motor inductance & 0.015 & henry \\
$K_{f m}$ & Motor constant & 0.032 & $\mathrm{Nm}$ \\
$J_{m 2}$ & Motor inertia & 0.0062 & $\mathrm{kgm}^{2}$ \\
$b_{m 2}$ & Motor damping & 0.0036 & $\mathrm{Nm} /(\mathrm{rad} / \mathrm{s})$ \\
$k_{s 2}$ & Lumped torque stiffness & 0.025 & $\mathrm{Nm}$ \\
$B_{\text {rack }}$ & Rack damping coefficient & 0.015 & $\mathrm{henry}$ \\
$M_{\text {rack }}$ & Rack lumped mass & 0.032 & $\mathrm{Nm}$ \\
$k_{l f}$ & Rack linkage stiffness & 0.00062 & $\mathrm{kgm}$ \\
$r_{L}$ & Offset of king pin axis & 0.00036 & $\mathrm{~m}$ \\
$r_{p}$ & Pinion gear radius & 0.025 & $\mathrm{~m}$ \\
$B_{k p}$ & King pin damping coefficient & 0.00062 & $\mathrm{kgm}^{2}$ \\
$I_{f}$ & Lumped front wheel inertia & 0.00036 & $\mathrm{kgm}^{2}$ \\
$k_{s 2}$ & Lumped torque stiffness & 0.025 & $\mathrm{Nm}^{2}$ \\
\hline
\end{tabular}

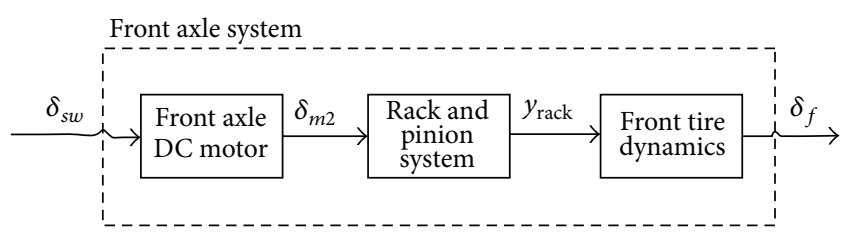

FIgURe 3: Block diagram of front axle subsystem.

The mathematical equation of the front axle DC motor is written as follows.

The front axle motor angular displacement is

$$
\ddot{\delta}_{m 2}=-\frac{b_{m 2}}{J_{m 2}} \dot{\delta}_{m 2}+\frac{k_{s 2}}{J_{m 2}} i_{a 2}
$$


and the front axle motor current is

$$
\dot{i}_{a 2}=-\frac{R_{2}}{L_{2}} i_{a 2}+\frac{k_{f m}}{L_{2}} \dot{\delta}_{m 2}+\frac{V_{s 2}}{L_{2}} .
$$

Consequently, the state equations of the front axle motor are given as

$$
\begin{aligned}
& \dot{x}_{f m}=A_{f m} x_{f m}+B_{f m} u_{f m}, \\
& y_{f m}=C_{f m} x_{f m}, \\
& x_{f m}=\left[\begin{array}{lll}
\dot{\delta}_{m 2} & \delta_{m 2} & i_{a 2}
\end{array}\right] .
\end{aligned}
$$

And $u_{f m}$ is the input to the front axle motor, while output is the rate change of front axle motor angular displacement $\left(\dot{\delta}_{m 2}\right)$, the front axle motor angular displacement $\left(\delta_{m 2}\right)$, and the current of front axle motor $\left(i_{a 2}\right)$.

The parameter states are written as follows:

$$
\begin{aligned}
A_{f m} & =\left[\begin{array}{ccc}
-\left(\frac{b_{m 2}}{J_{m 2}}\right) & 0 & \frac{k_{s 2}}{J_{m 2}} \\
1 & 0 & 0 \\
-\left(\frac{k_{f m}}{L_{2}}\right) & 0 & -\left(\frac{R_{2}}{L_{2}}\right)
\end{array}\right], \\
B_{f m} & =\left[\begin{array}{c}
0 \\
0 \\
\frac{1}{L_{2}}
\end{array}\right] \\
u_{f m}= & \delta_{s w}=V_{s 2} .
\end{aligned}
$$

The rack and pinion system is

$$
\begin{gathered}
\ddot{y}_{\text {rack }}=\frac{1}{M_{\text {rack }}}\left[\left(-\frac{2 k_{l f} y_{\text {rack }}}{r_{L}^{2}}\right)-\left(\frac{k_{s 2} y_{\text {rack }}}{r_{p}^{2}}\right)\right. \\
\left.-B_{\text {rack } f} \dot{y}_{\text {rack }}+\left(\frac{k_{s 2} \delta_{m 2}}{r_{p}}\right)\right] .
\end{gathered}
$$

And $u_{y \text { rack }}$ is considered the input of the rack and pinion system, and the output is the rack displacement $\left(y_{\text {rack }}\right)$ and the parameter states are as follows:

$$
\begin{aligned}
& A_{y \text { rack }} \\
& =\left[-\left[\left(\frac{2 k_{l f}}{M_{\text {rack }} r_{L}^{2}}\right)+\left(\frac{k_{s 2}}{M_{\text {rack }} r_{p}^{2}}\right)\right]-\left(\frac{B_{\text {rack }}}{M_{\text {rack }}}\right)\right], \\
& B_{y \text { rack }}=\left[\left(\frac{k_{s 2}}{M_{\text {rack }} r_{p}}\right)\right], \\
& u_{y \text { rack }}=\delta_{m 2}
\end{aligned}
$$

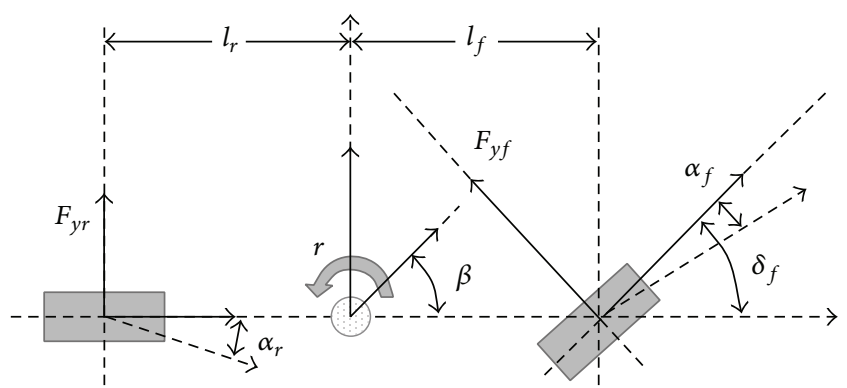

FIgURE 4: Single track-linear vehicle model.

and the front tire dynamic is

$$
\ddot{\delta}_{f}=\frac{1}{I_{f}}\left[\left(-k_{l f} \delta_{f}+\left(\frac{k_{l f} y_{\text {rack }}}{r_{L}}\right)-B_{k p} \dot{\delta}_{f}\right)\right]
$$

and $u_{\text {tire }}$ is considered the input of the front tire dynamic. The output is the front tire angle $\left(\delta_{f}\right)$ and the parameter state is

$$
\begin{aligned}
& \left.A_{\text {tire }}=\left[\begin{array}{c}
0 \\
1 \\
I_{f}
\end{array}\right)-\left(\frac{k_{l f}}{I_{f}}\right)\right], \\
& B_{\text {tire }}=\left[\left(\frac{k_{l f}}{I_{f} r_{L}}\right)\right], \\
& u_{\text {tire }}=y_{\text {rack }} .
\end{aligned}
$$

2.3. Single Track-Linear Vehicle Model. The stability characteristics of a steer-by-wire vehicle are affected by the influence of front tires via the feedback of the vehicle dynamic response. Thus, it is necessary to develop a single track-linear vehicle model as mentioned by author $[16,18-21]$ in simulation and experimental validation. The single track linear vehicle model is shown in Figure 4. In this paper, the aim is to model the linear vehicle in order to generate the estimation of self aligning torque $\left(\tau_{a}\right)$. This acts as the disturbance input to the front axle system and assures the road contact with front tire. The dynamics of single track-linear vehicle model is represented by bicycle model where the states contain yaw rate $(r)$ and vehicle body slip angle $(\beta)$

The following assumptions are considered for normal driving maneuverer. These assumptions could simplify the vehicle model [18]:

(i) friction force in the $x$-direction is negligible,

(ii) vehicle speed is constant,

(iii) angle for right and left tire is approximately the same. 
With the aforementioned assumptions, the derived equations of the motion of yaw rate $(r)$ and vehicle body slip angle $(\beta)$ are shown in (13) as follows:

$$
\begin{aligned}
\dot{r}= & {\left[\frac{\left(l_{f}^{2} C_{f}+l_{r}^{2} C_{r}\right)}{I_{s} V}\right] r+\left[\frac{\left(l_{r}^{2} C_{r}-l_{f}^{2} C_{f}\right)}{I_{s}}\right] \beta } \\
& +\left[\frac{\left(l_{f} C_{f}\right)}{I_{s}}\right] \delta_{f}, \\
\dot{\beta}= & {\left[1+\frac{\left(l_{r} C_{r}-l_{f} C_{f}\right)}{m V^{2}}\right] r-\left[\frac{\left(C_{f}+C_{r}\right)}{m V}\right] \beta } \\
& +\left[\frac{C_{f}}{m V}\right] \delta_{f} .
\end{aligned}
$$

In the linear tire region, lateral force at the front and rear is related to slip angle by cornering stiffness of the front and rear tires written as follows:

$$
\begin{aligned}
& F_{y f}=-C_{f} \alpha_{f}, \\
& F_{y r}=-C_{r} \alpha_{r} .
\end{aligned}
$$

At a larger slip angle, the relation between lateral force and slip angle becomes nonlinear. By assuming a smaller slip angle approximation, the slip angle is written in terms of vehicle body slip angle and yaw rate that are considefed as follows:

$$
\begin{gathered}
\alpha_{f}=\left(\beta+\frac{l_{f}}{V} r-\delta_{f}\right), \\
\alpha_{r}=\left(\beta+\frac{l_{r}}{V} r-\delta_{r}\right) .
\end{gathered}
$$

Rewriting (13) into state space form, we have

$$
\begin{aligned}
& \dot{x}_{v m}=A_{v m} x_{v m}+B_{v m} u_{v m}, \\
& y_{v m}=C_{v m} x_{v m}, \\
& x_{v m}=\left[\begin{array}{ll}
r & \beta
\end{array}\right] .
\end{aligned}
$$

And $u_{v m}$ is considered the input to the linear vehicle model, while the yaw rate $(r)$ and vehicle body slip angle $(\beta)$ are the output of the linear vehicle model. The parameter state is written as follows:

$$
\begin{aligned}
A_{v m} & =\left[\begin{array}{cc}
\left(\frac{\left(L_{f}^{2} C_{f}+L_{r}^{2} C_{r}\right)}{I_{s} V}\right) & -\frac{\left(L_{r} C_{r}-L_{f} C_{f}\right)}{I_{s}} \\
1+\left(\frac{\left(L_{r} C_{r}-L_{f} C_{f}\right)}{m V^{2}}\right) & -\frac{\left(C_{f}+C_{r}\right)}{m V}
\end{array}\right], \\
B_{v m} & =\left[\begin{array}{c}
\frac{L_{f} C_{f}}{I_{s}} \\
\frac{C_{f}}{m V}
\end{array}\right], \\
u_{v m} & =\delta_{f} .
\end{aligned}
$$

The parameter of a linear vehicle model directly can be measured, but some parameters need to be estimated. There are several methods to estimate the model parameter $[22,23]$. A method based on Sahoo et al. [22] is used to estimate the model parameters with assumption that the vehicle mass is distributed to front and rear of each tire. The total of vehicle mass $(m)$ that is based on the front $\left(m_{f}\right)$ and rear $\left(m_{r}\right)$ tire masses is written as follows:

$$
m=m_{f}+m_{r}
$$

when

$$
\begin{aligned}
& m_{f}=m_{f l}+m_{f r}, \\
& m_{r}=m_{r l}+m_{r r},
\end{aligned}
$$

where $m_{f l}, m_{f r}, m_{r l}$, and $m_{r r}$ are the masses of the vehicle at front left, front right, rear left, and rear right, respectively. The parameter length of wheel base $(l)$ which is sum of length from a center of front tire $l_{f}$ and rear tire $l_{r}$ to C.O.G of vehicle body is written as follows:

$$
l=l_{f}+l_{r}
$$

while the inertia of vehicle $I_{s}$ that is approximated by assuming the vehicle as two point masses joined with mass-less road [22] is written as follows:

$$
I_{s}=m_{f} l_{f}^{2}+m_{r} l_{r}^{2}
$$

The front cornering stiffness $C_{f}$ and rear cornering stiffness $C_{r}$ parameters are written in (22) by assuming that the type of radial tire is used and cornering stiffness per degree of slip angle is approximately $16-17 \%$ of the load on the tire [22]. Consider

$$
\begin{aligned}
C_{f} & =m_{f} * g * 0.165(\mathrm{~N} / \mathrm{deg}), \\
C_{r} & =m_{r} * g * 0.165(\mathrm{~N} / \mathrm{deg}) .
\end{aligned}
$$

The parameters of the linear vehicle model are illustrated in Table 3.

\section{Force Feedback Torque Estimation Control Algorithm}

It has been known that the force feedback torque for driver steering feel should be created artificially, due to the elimination of mechanical column shaft in SBW system.

Moreover, the proportion of the steering feel obtained should be similar to conventional steering system. For this reason, the steering wheel in SBW system that is equipped with the motor actuator is used to generate the steering feel by controlling the total feedback torque $\left(\tau_{\text {total feedback }}\right)$. A schematic block diagram of the proposed force feedback torque control is shown in Figure 5.

Based on Figure 5, the total force feedback torque consists of the torque of front axle motor $\left(\tau_{f m}\right)$, torque on steering wheel motor $\left(\tau_{s m}\right)$, and compensation torque, which is the inertia $\left(\tau_{\text {inertia }}\right)$ and damping torque $\left(\tau_{\text {damp }}\right)$. Meanwhile, the 


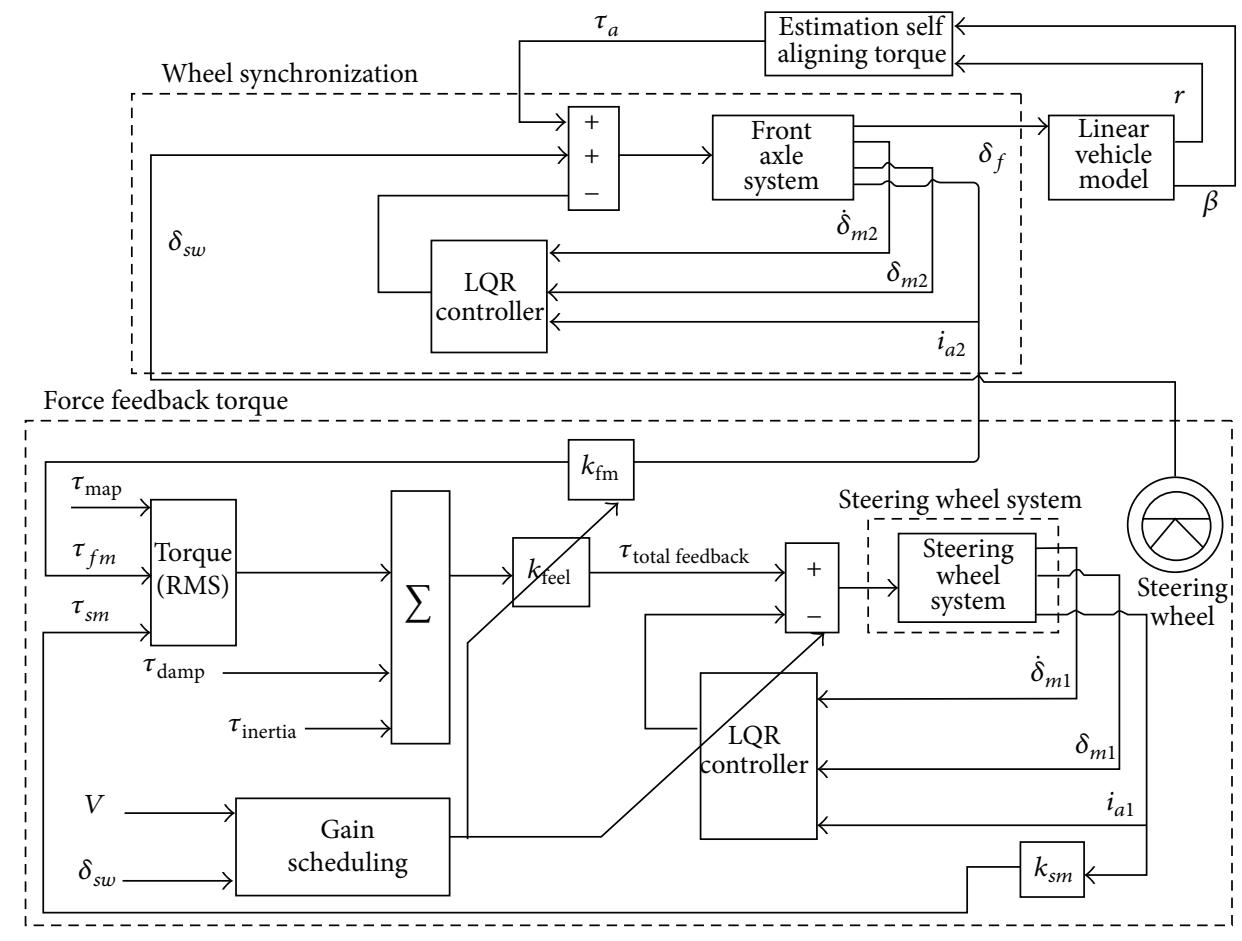

FIGURE 5: Overview of force feedback torque control algorithm for SBW system.

TABLE 3: Linear vehicle model [16].

\begin{tabular}{llcc}
\hline Parameter & Description & Value & Unit \\
\hline$C_{f}$ & Front cornering stiffness & 40000 & $\mathrm{~N} / \mathrm{rad}$ \\
$C_{r}$ & $\begin{array}{l}\text { Rear cornering stiffness } \\
\text { Length from center front } \\
l_{f}\end{array}$ & 35000 & $\mathrm{~N} / \mathrm{rad}$ \\
$l_{r}$ & $\begin{array}{l}\text { Leneel to (C.O.G) vehicle } \\
\text { wheel to C.O.G vehicle }\end{array}$ & 1.4 & $\mathrm{~m}$ \\
$m$ & Mass of the vehicle & 1535 & $\mathrm{~m}$ \\
$I_{s}$ & Inertia of vehicle & 2149 & $\mathrm{~kg}$ \\
$V$ & Speed of vehicle \\
$F_{y f}$ & Front tire lateral force & - & $\mathrm{km} / \mathrm{h}$ \\
$F_{y r}$ & Rear tire lateral force & - & $\mathrm{Nm}$ \\
$\alpha_{f}$ & Front tire slip angle & - & $\mathrm{Nm}$ \\
$\alpha_{r}$ & Rear tire slip angle & - & $\mathrm{Nm}$ \\
\hline
\end{tabular}

torque map is based on the function of the steering wheel angle and vehicle speed is added to the total feedback torque. Moreover, a steering feel gain $\left(k_{\text {feel }}\right)$ is adapted based on the function of steering wheel angle and vehicle speed to vary the feedback torque. In order to control the feedback torque, the gain scheduling with LQR controller is used. To show the influence of the tire on the road surface, the self aligning torque $\left(\tau_{a}\right)$ acts as input disturbance to the front axle system as follows:

$$
\tau_{a}=-C_{f}\left(t_{p}+t_{m}\right)\left[\beta+\frac{l_{f} r}{V}-\delta_{f}\right] \mu,
$$

where $\mu$ is coefficient for road dry condition, pneumatic trail $\left(t_{p}\right)$, and mechanical trail $\left(t_{m}\right)$.

On the other hand, any change of the road surface could change the feedback torque magnitude of the front axle motor. Furthermore, the LQR controller of the front axle system is used to synchronize the front tire angle $\left(\delta_{f}\right)$ with driver input steering wheel angle $\left(\delta_{s w}\right)$ by controlling the angle of the front axle motor $\left(\delta_{m 2}\right)$ in accordance with the steering ratio.

Thus, based on the proposed control algorithm, the total force feedback torque to the steering wheel system is written as follows:

$$
\begin{aligned}
& \tau_{\text {total feedback }}=\left(\left[\left(\sqrt{\text { mean }\left(\tau_{\text {sm }}+\tau_{f m}+\tau_{\text {map }}\right)}\right)\right]\right. \\
& \left.+\tau_{\text {inertia }}+\tau_{\text {damp }}\right) k_{\text {feel }} .
\end{aligned}
$$

Author $[9,10]$ has generated and discussed the force feedback torque using the torque map concept. The torque map is based on the function of the steering wheel angle and vehicle speed parameter. The feedback torque is determined by two control parameters, $\left(k_{\beta}\right)$ for the vehicle speed and $\left(k_{\alpha}\right)$ for the steering wheel angle function.

The torque based on the function of vehicle speed is given as follows [9]:

$$
\tau_{1}=k_{\beta} x^{2}\left(\frac{1}{3} x-\frac{1}{2} V_{\max }\right)+T_{\mathrm{in}},
$$




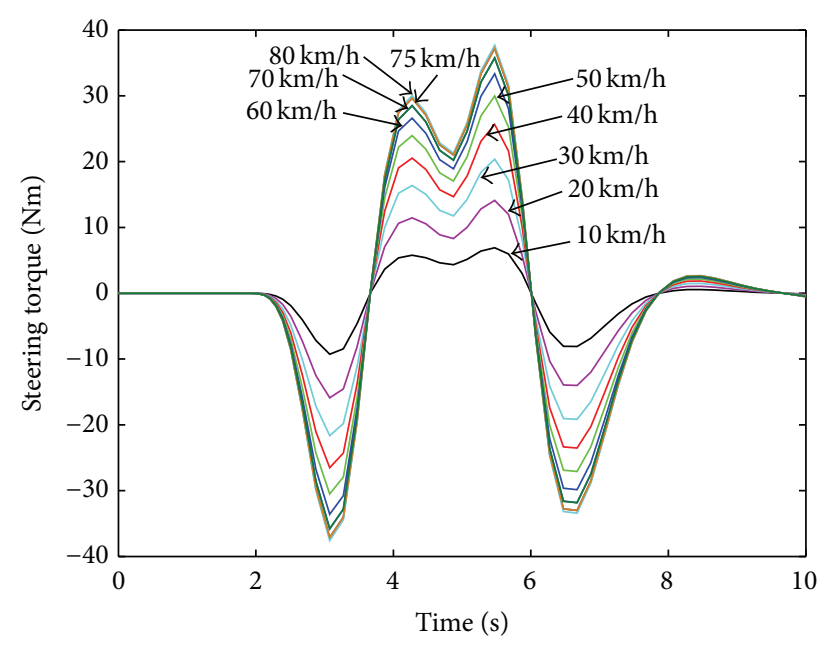

FIGURE 6: Steering torque based on torque map at different speed.

where $(x)$ is initial velocity and $\left(V_{\max }\right)$ is maximum velocity, while the torque based on a function of steering wheel angle is written as follows [9]:

$$
\tau_{2}=k_{\alpha} \sqrt{\left|\delta_{s w}\right|} \operatorname{sgn} \delta_{s w}
$$

Based on the torque map concept, the results of steering torque at different vehicle speed are shown in Figure 6 when the input steering wheel angle is a double lane change manoeuvre. The torque increased at high speed and decreased at low speed $[9,24]$. By varying the two control parameters, the steering reactive torque changes at different torque magnitude. However, the feedback torque based on the torque map concept did not create the artificial steering feel due to the fact that no element of road contact such as vehicle dynamic responses are feedback to the torque map model. Thus, driver not sense realistic driver steering feel.

Thus, for this reason the front axle motor torque and steering wheel motor torque are added to the torque map. These ensure that the driver senses the feedback torque from road contact. The front axle motor torque is chosen due to its proportion to the road surface. The reaction torque of the road surface gives the effect to the rack and pinion system and it connects to the front axle DC motor. Thus, the front axle motor torque would always be proportional to the road surface. Any changes in road surface will influence the front axle motor torque. In order to measure the torque at the front axle motor, the direct current measurement technique is used to estimate the torque.

The direct relationship between torque and current of a motor can be defined [25]. Thus, then front axle motor torque $\left(\tau_{f m}\right)$ that consists of the front axle motor constant $\left(k_{f m}\right)$ and the motor current $\left(i_{a 2}\right)$ is written as follows:

$$
\tau_{f m}=i_{a 2} k_{f m}
$$

and the corresponding steering wheel motor torque $\left(\tau_{s m}\right)$ that consists of the steering wheel motor constant $\left(k_{s m}\right)$ and the motor current $\left(i_{a 1}\right)$ is written as follows:

$$
\tau_{s m}=i_{a 1} k_{s m} \text {. }
$$

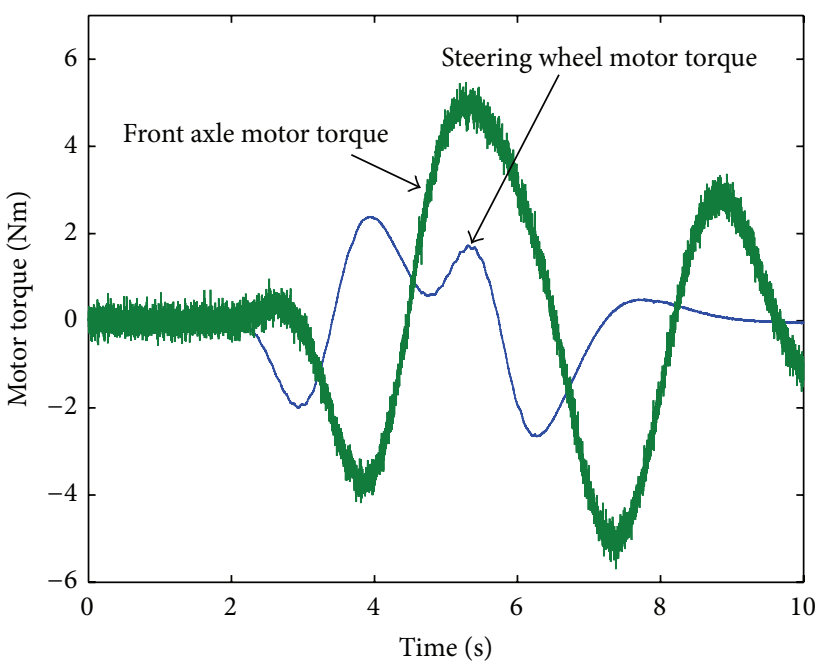

FIGURE 7: Steering wheel and front axle motor torque at $80 \mathrm{~km} / \mathrm{h}$.

Figure 7 shows the front axle motor and steering wheel motor torque response when the input is a double lane change manoeuvre. The results show that the front axle motor gives a high torque. This is due to the fact that the input disturbance torque between the tire and road surface which is the self aligning torque has an effect on the front axle motor. Increasing the vehicle speed will increase the front axle motor torque. On the other hand, the magnitude of steering wheel motor torque is decreased due to the elimination of mechanical column shaft and is not affected by the self aligning torque.

The phase compensation torque consists of the inertia torque and damping torque potential to recreate the artificial steering feel of the conventional steering system. Moreover, it is intended to adjust the steering feel, reduce the vibration, and stabilize the system. Due to this fact, the element of compensation torque is taken in order to improve the feedback torque for a driver steering feel and to stabilize the system.

The damping torque $\left(\tau_{\text {damp }}\right)$ which is the rate change of the steering wheel motor angle $\left(\dot{\delta}_{m 1}\right)$ and the damping gain $\left(k_{\text {damp }}\right)$ is written as follows:

$$
\tau_{\text {damp }}=\dot{\delta}_{m 1} k_{\text {damp }} .
$$

The inertia torque $\left(\tau_{\text {inertia }}\right)$ that is the acceleration of the steering wheel motor angle $\left(\ddot{\delta}_{m 1}\right)$ and the inertia gain $\left(k_{\text {inertia }}\right)$ is written as follows:

$$
\tau_{\text {inertia }}=\ddot{\delta}_{m 1} k_{\text {inertia }}
$$

The inertia and damping torque responses are shown in Figure 8 when the input steering wheel angle is a double lane change manoeuvre. It is obtained that the damping torque gives a smooth signal and reduces the vibration. Meanwhile, the inertia torque gives high magnitude. Thus, the combination between the inertia torque and damping torque not only provides an average of steering feel, but is also able to stabilize the system at the same time. Figure 9 shows the feedback 


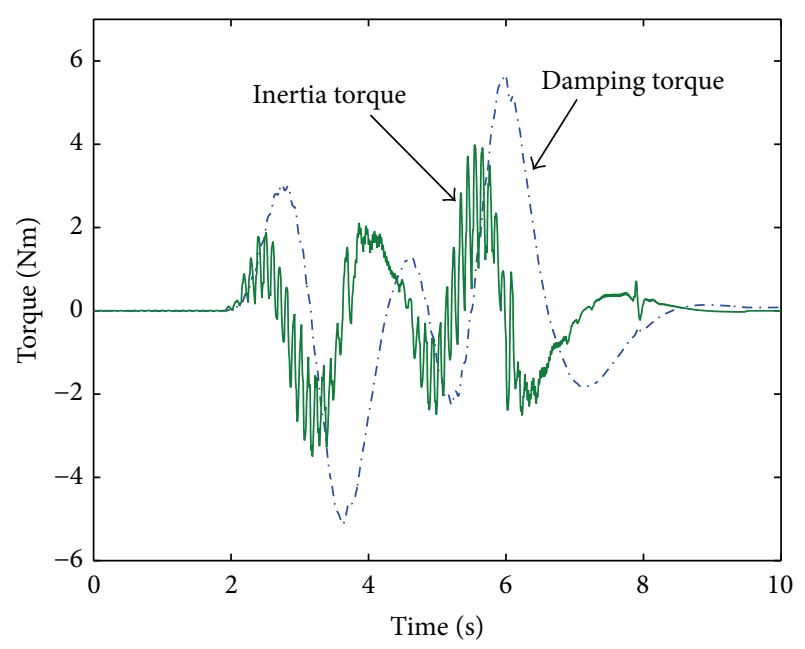

FIGURE 8: Inertia and damping torque.

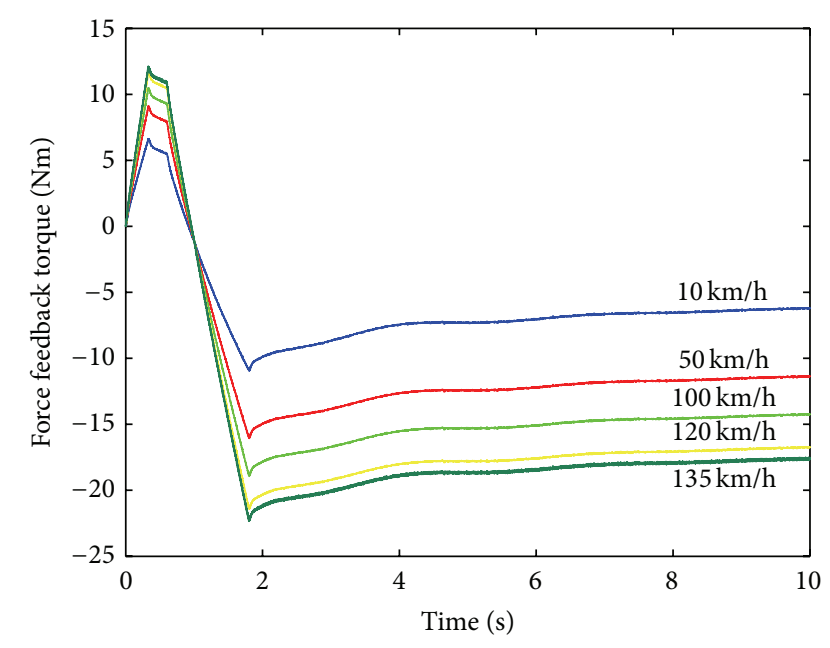

FIGURE 9: Proposed force feedback torque response at different vehicle speed.

torque response based on (24). The torque is increased according to the vehicle speed. The higher vehicle speed will increase the feedback torque and vice versa due to the same fact that is proposed by torque map.

3.1. Linear Quadratic Regulator (LQR) Controller. The LQR controller provides the best possible performance to control and stabilize the system by changing the location of the poles of the system to the optimal location for a time response, overshoot, and steady state. This is done by designing the state feedback control $K$ that minimized cost function $J$ to stabilize the system. In this paper, the LQR controller is used firstly to control the front axle motor angle for the wheel synchronization and secondly to control the steering wheel motor for a feedback torque.

The wheel synchronization or directional control is a basic characteristic for steering function, where a front tire

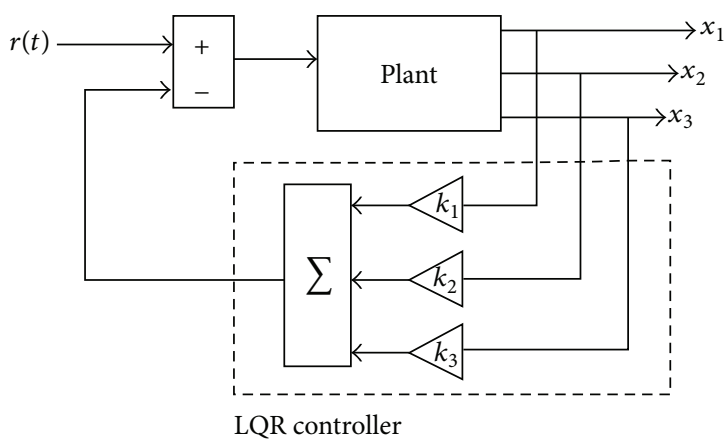

FIGURE 10: Basic control block diagram of LQR controller.

angle should follow driver input steering wheel angle according to the steering ratio. This is done by controlling the angle of the front axle motor. In the LQR control schemes, a feedback gain matrix is designed to achieve some compromise between the use of control effort, the magnitude, and the speed of response that will guarantee a stable system. Figure 10 shows the control block diagram of the LQR controller.

The optimal LQR problem is often defined more generally and consists of finding controller transfer matrix that minimizes the cost function $J$ that is written as follows:

$$
J=\int_{0}^{\infty}\left(x^{T} Q x+u^{T} R u\right) d t,
$$

where $x^{T}$ and $U^{T}$, respectively, represent the transpose of the state and input vector. The $Q$ and $R$ are positive definite (or positive-semi definite) real symmetric matrix. The $Q$ and $R$ are usually chosen to be diagonal matrix written as follows:

$$
\begin{aligned}
Q_{i i} & =\frac{1}{\text { maximum acceptable value of } x_{i}^{2}}, \\
R_{j j} & =\frac{1}{\text { maximum acceptable value of } u_{j}^{2}},
\end{aligned}
$$

where

$$
\begin{aligned}
& i=\varepsilon\{1,2, \ldots, \ell\}, \\
& j=\varepsilon\{1,2, \ldots, j\} .
\end{aligned}
$$

In essence, Bryson's rule scales the variables that appear in $J$ so that the maximum acceptable value for each term is one. This is especially important when the units used for the different components of $u$ and $x$ make the values for these variables numerically very different from each other.

Assume that the steering ratio is $15: 1$ and the gains of the LQR controller are $[0.1,0.98,0.008]$. Figure 11 shows a response of the front axle system when the input steering wheel angle is a step function as shown in Figure 11(a).

The results show that the angle of the front axle motor has a fast response compared to the EPS steering system. 


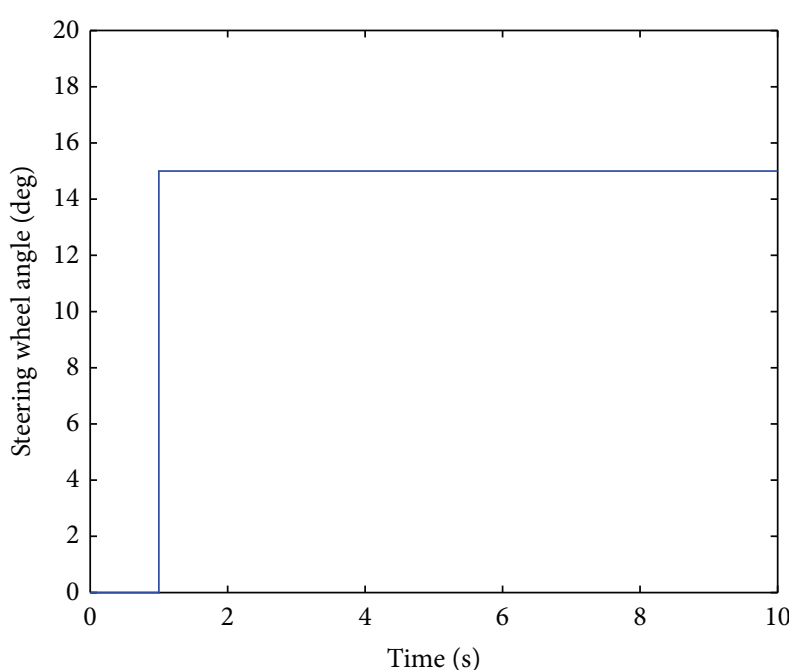

(a) Steering wheel angle

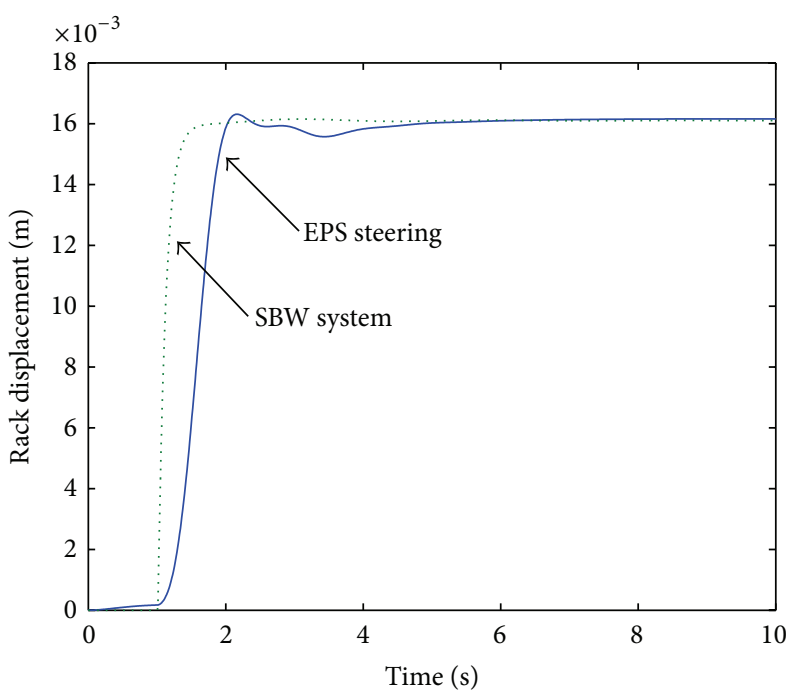

(c) Rack displacement

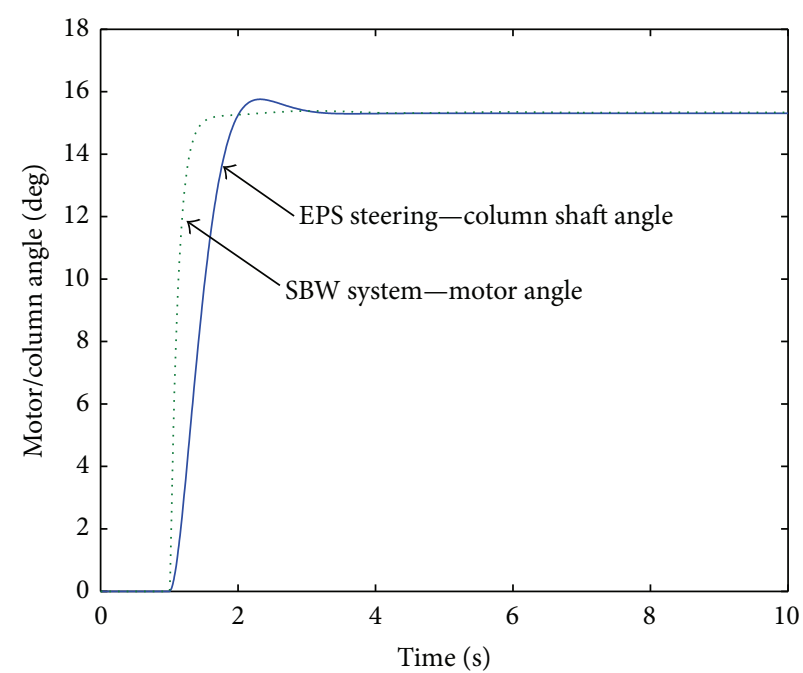

(b) Front axle motor angle

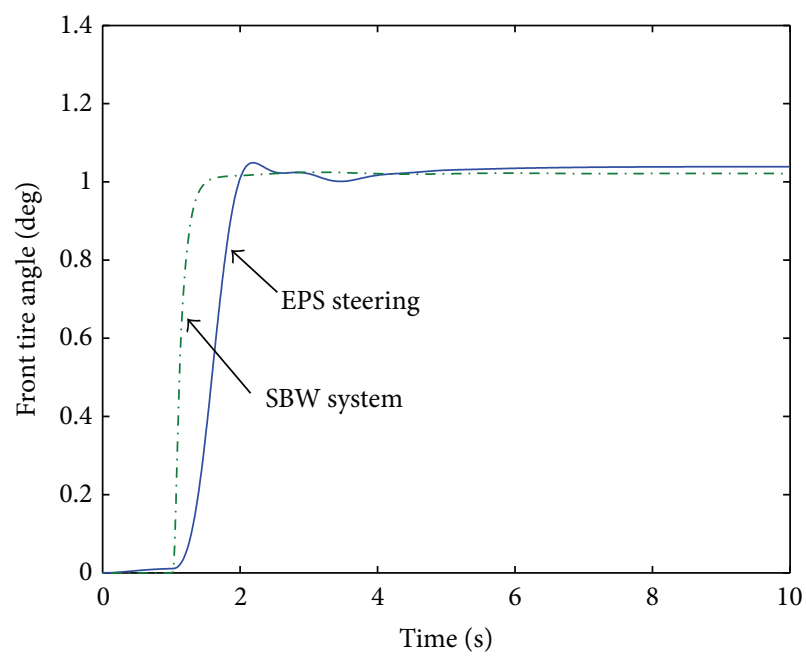

(d) Front tire angle

FIGURE 11: Front axle system response for wheel synchronization.

Moreover, the LQR controller is able to reduce the delay caused by the self aligning torque created from the contact between the tire and road surfaces. This not only improved the vehicle stability, but also ensured that the driver has a more confident level during manoeuvre. Compared to the EPS steering system, the delay caused by mechanical column shaft connected to the steering wheel system. Furthermore, it can be seen that the front tire angle is at almost fairly close to $1^{\circ}$ as shown in Figure 11(d). However, it has small chattering due to the self aligning torque. However, with wide range adjustment gains of the LQR controller the steering response could be improved.

3.2. Gain Scheduling (GS) with LQR Controller. In certain situations, the dynamic behaviour of the process changed in accordance with the conditions of the process. This situation could affect the stability of the system if not to control properly. Thus, it is possible to change the gains of the controller by monitoring the operating conditions of the process to have a stable system. The gain scheduling (GS) technique is used to change the gain of the LQR controller in order to control the feedback torque and the steering feel gain $\left(k_{\text {feel }}\right)$ is used to increase and decrease the torque. It is important to increase the feedback torque at high speed for steering stability and to decrease it in low speed, especially during parking, to improve vehicle manoeuvre [9]. This is based on the steering wheel angle and vehicle speed function in order to achieve the feedback torque for the real driver steering feel.

The relationship between a gain scheduling with LQR controller is shown in Table 4 . The vehicle speed is divided into 3 categories at low speed $(0-30 \mathrm{~km} / \mathrm{h})$, medium speed $(31-100 \mathrm{~km} / \mathrm{h})$, and high speed $(101-120 \mathrm{~km} / \mathrm{h})$. The maximum vehicle speed is limited to $120 \mathrm{~km} / \mathrm{h}$. The steering wheel 


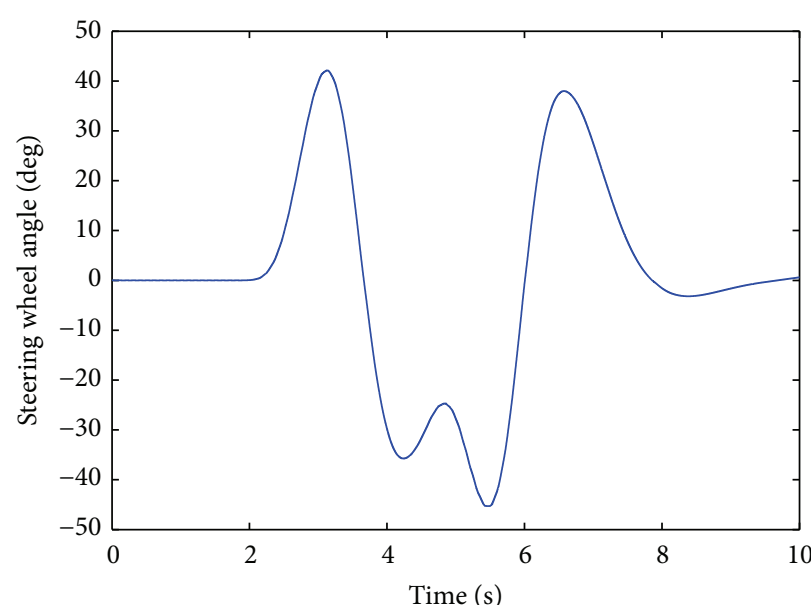

(a) Input steering wheel angle

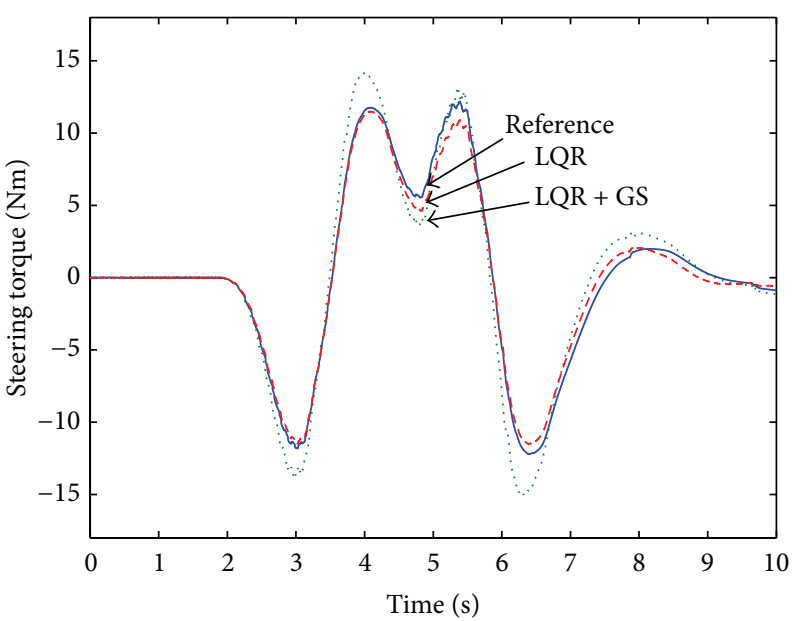

(c) $\mu=1.4$

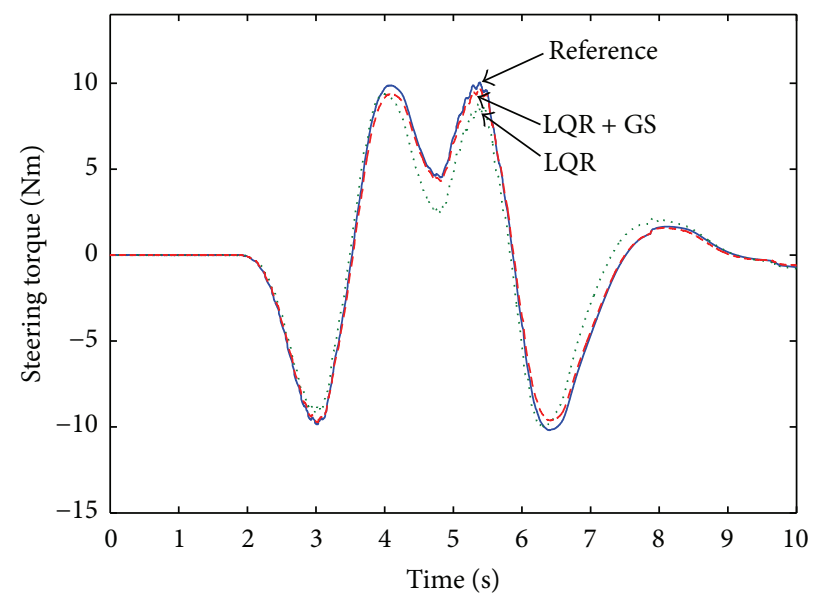

(b) $\mu=1$

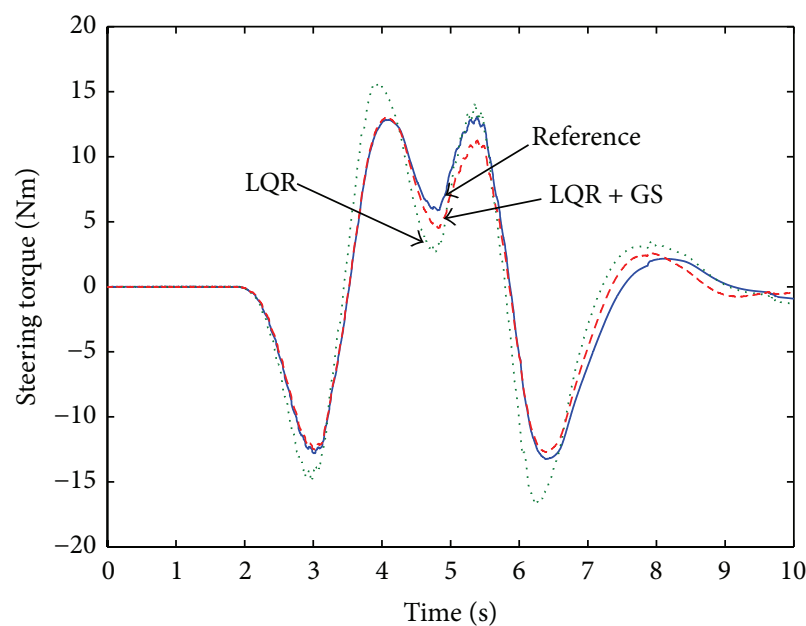

(d) $\mu=1.7$

FIGURE 12: Comparison of torque response of LQR and LQR + GS controller at different $\mu$.

TABLE 4: The gains of LQR controller and steering feel.

\begin{tabular}{lccccc}
\hline$V(\mathrm{~km} / \mathrm{h})$ & $\delta_{s w}($ degree $)$ & $k_{1}$ & $k_{2}$ & $k_{3}$ & $k_{\text {feel }}$ \\
\hline$(0-30)$ & $\left( \pm 180^{\circ}<\delta_{s w}< \pm 405^{\circ}\right)$ & 0.03 & 0.65 & 0.001 & 0.14 \\
$(31-100)$ & $\left( \pm 46^{\circ}<\delta_{s w}< \pm 179^{\circ}\right)$ & 0.03 & 0.84 & 0.001 & 0.60 \\
$(101-120)$ & $\delta_{s w} \leq+45^{\circ}$ or $\delta_{s w} \leq-45^{\circ}$ & 0.05 & 0.95 & 0.001 & 0.95 \\
\hline
\end{tabular}

angle is also divided into 3 categories according to vehicle speed condition. The notation "+" means that the driver turned the steering wheel clockwise and notation “-” is used for counter clockwise, in which the maximum steering wheel turn is $\pm 405^{\circ}$.

The gains of the LQR controller are defined using Bryson's rule method and the steering feel gain is defined using intuitive and has a range from 0.1 to 1 . This range has been defined for various speeds: $10 \mathrm{~km} / \mathrm{h}, 80 \mathrm{~km} / \mathrm{h}$, and $120 \mathrm{~km} / \mathrm{h}$ after comparing with EPS steering system [15]. For example, if the driver turns a steering wheel between $\left( \pm 180^{\circ}<\delta_{s w}<\right.$ $\pm 405^{\circ}$ ) and vehicle speed is $10 \mathrm{~km} / \mathrm{h}$, the total feedback torque is multiplied by steering feel gain $k_{\text {feel }}=0.14$. Thus, the feedback torque is decreased, which results in making the driver feel it easier turning the steering wheel and improves vehicle manoeuvre. The feedback torque is regulated by LQR controller when the gains are $k_{1}=0.03, k_{2}=0.65$, and $k_{3}=0.001$. The gains are the optimum, that has been assured by providing a better torque control based on vehicle speed and steering wheel angle function.

Comparing torque response between LQR and LQR + GS controller for different coefficient $(\mu)$ is shown in Figure 12 when the input steering wheel angle is a double lane change manoeuvre as shown in Figure 12(a). The vehicle speed is set to be $80 \mathrm{~km} / \mathrm{h}$. Based on results obtained, the LQR + GS technique offers an improvement $90 \%$ and the curve trend is almost similar to reference torque compared to the LQR controller. This is because the gains of LQR controller changed based on the steering wheel angle and vehicle speed parameter which is able to reject the uncertainty torque of a road condition. Meanwhile, with the fixed gains of the LQR controller, it has an excessive torque that can cause the system to be unstable. The RMS torque values are illustrated in Table 5. 
TABLE 5: Comparison of RMS torque values of LQR and LQR + GS controller.

\begin{tabular}{lccc}
\hline & Reference & LQR & LQR + GS \\
\hline$\mu=1$ & 5.6361 & 5.0795 & 5.5450 \\
$\mu=1.4$ & 6.1218 & 6.8339 & 5.7243 \\
$\mu=1.7$ & 6.6184 & 7.2888 & 6.2080 \\
\hline
\end{tabular}

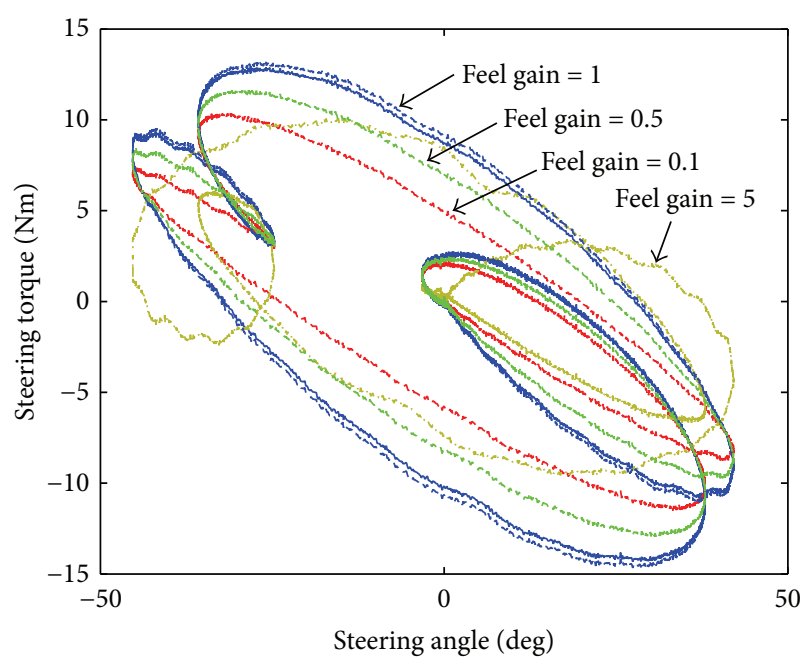

(a) Different steering feel gain at $80 \mathrm{~km} / \mathrm{h}$

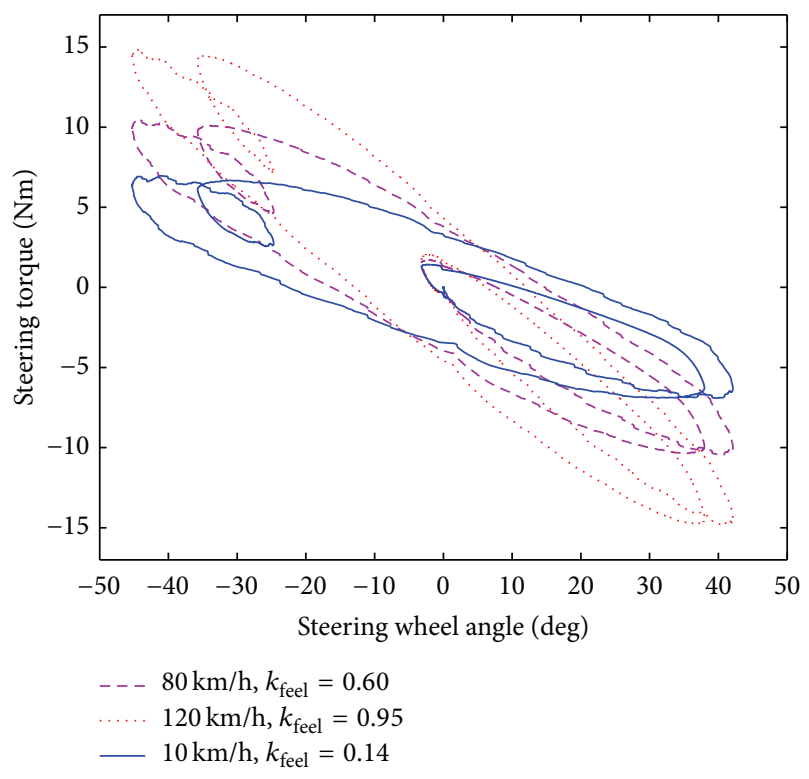

(b) Different steering feel gain at various speed

FIGURE 13: Steering feel gains response at various vehicle speed.

Figure 13(a) shows the steering torque with respect to steering wheel angle when different steering feel gain is used at various vehicle speeds. It is observed that when the steering feel gain is increased at maximum range, which is 1 , the steering torque will increase and driver will sense stiffer on the steering wheel at high speed manoeuvre. Meanwhile, when decreasing the steering feel gain, this will result in reducing the steering torque. Thus, the driver will sense softer

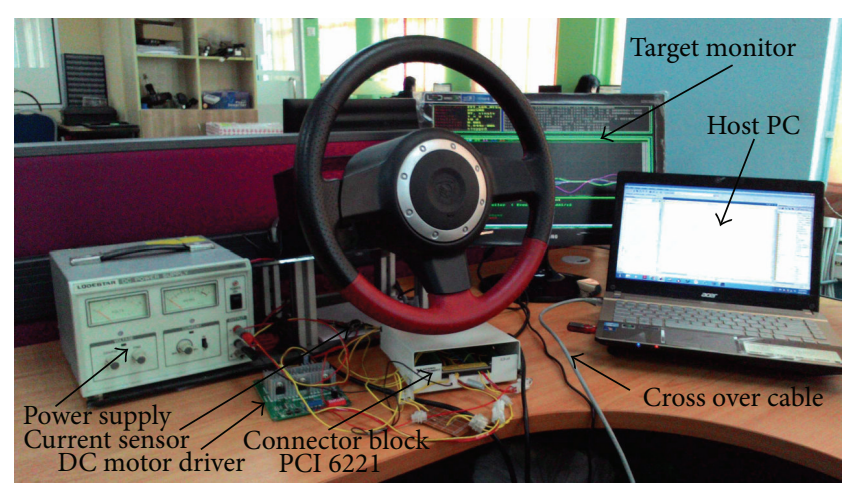

FIGURE 14: Steering wheel system, hardware overview.

during turning the steering wheel at the low speed manoeuvre. However, when the steering feel gain is 5 which exceeds its maximum limit, the steering torque becomes unstable. Figure 13(b) shows the steering feel gains at various speeds. At high speed of $120 \mathrm{~km} / \mathrm{h}$, the steering feel gain is increased, and this will increase the steering torque for steering stability. Meanwhile, at low speed, the steering feel gain is decreased, which will help improve vehicle manoeuvre especially during parking. Based on the proposed gain scheduling with the LQR controller, not only does it provide better control on the steering torque, but also it is optional for a designer to have a wide range adjustment to vary the steering torque for a better driver steering feel and to improve vehicle manoeuvre.

\section{Hardware in the Loop (HIL) and Result}

For hardware in the loop (HIL) setup, the front axle system and linear vehicle model are simulated on the host computer. The steering wheel system is replaced by HIL mechanism. The position of the steering wheel motor is measured using a rotary encoder with 500 pulses per revolution. To measure the steering wheel torque, the current sensor is connected in series with the DC motor driver. The steering wheel DC motor has a torque $12.9 \mathrm{Nm}$ with $100 \mathrm{rpm}$. The single track linear vehicle model is used to generate the estimation self aligning torque as element to the feedback torque and disturbance to the front axle system. The HIL system is executed under $1 \mathrm{~ms}$ sampling time and interfaced using Matlab-XPC target toolbox configuration as shown in Figures 14 and 15.

The assumptions through the experiment are listed as follows:

(i) the vehicle cruises at constant speed,

(ii) the condition of dry asphalt road $(\mu=0.85)$.

The experiments are done under high, medium, and low speed manoeuvre [26]. The same input steering wheel angle between simulation and experiment is given. Therefore, the result obtained from real time control is compared with the electronic power steering (EPS) system [15].

4.1. Motor Model Validation for Steering Wheel System. Although the model of steering wheel system has been 


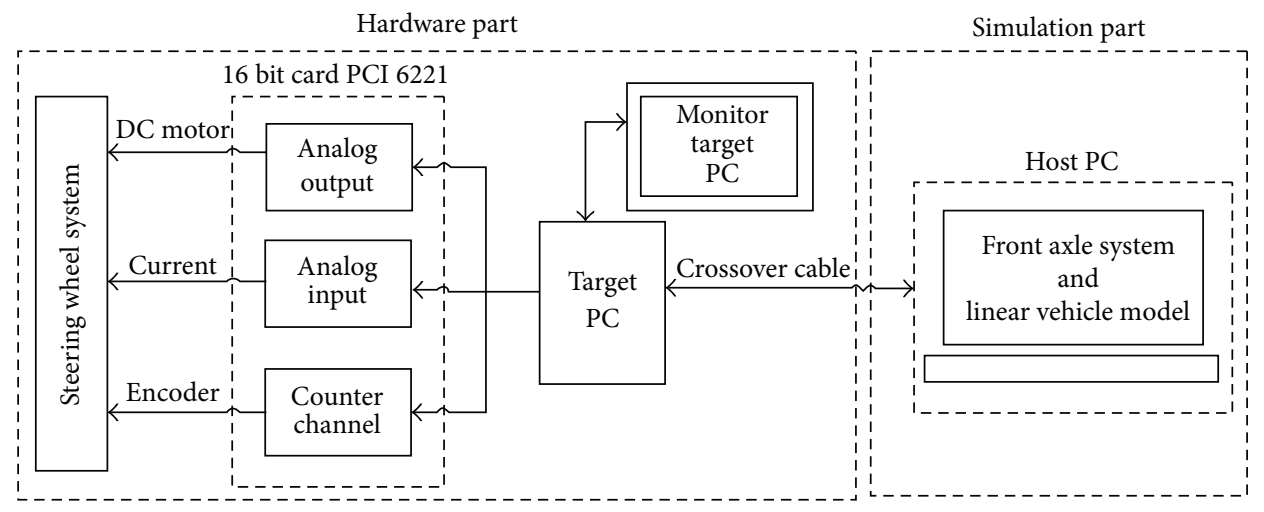

FIGURE 15: Block diagram of the steering wheel-XPC target interfaced.

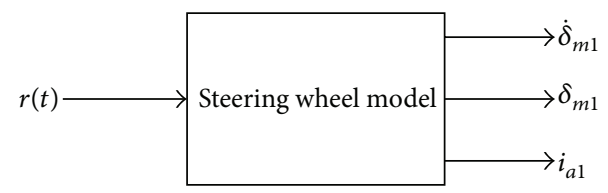

FIGURE 16: Block diagram motor model validation for steering wheel system.

derived, the model validation is necessary to ensure the system is fairly able to adequate for real time application. This section describes the motor model validation of steering wheel system. The block diagram is shown in Figure 16.

The input signal is $r(t)$ and the output is rate change of motor $\left(\dot{\delta}_{m 1}\right)$, motor position $\left(\delta_{m 1}\right)$, and the motor current $\left(i_{m 1}\right)$. The measured output response is then used and compared with simulation to estimate the parameter of the steering wheel model using the Matlab tool software. The measured output data are taken based on the open loop system, when the input to the system is sinusoidal signal with amplitude of $\pm 45^{\circ}$ for $10 \mathrm{sec}$. The Gaussian method is used to estimate the parameters of the steering wheel motor. The comparison between simulation and measured output is shown in Figure 17. It is obtained that the output of the simulation is almost identical to the measured output. However, small difference errors occur due to the small parametric uncertainties that have not been modelled. The parameter estimation value is illustrated in Table 6.

4.2. Noise Filtering. Both analog and digital devices have a trait of noise or unwanted features that have effect on the system performance such as electromagnetic interference. The noise could be either random or white noise. Attenuation of this noise is often as a primary goal in control system application and in particular when controlling the process system. The average value of noise typically is zero which will give misreading information to the process and it would not be possible to control the process. In order, to reduce the noise inference, filtering technique is used. A filter is used to remove unwanted noise. It removes some noise frequencies to suppress interfacing signal and reduce background noise.
TABLE 6: Parameter estimation for DC motor steering wheel system.

\begin{tabular}{lccc}
\hline Parameter & Value & Estimation value & Unit \\
\hline$R_{1}$ & 4.405 & 5.64 & ohm \\
$L_{1}$ & 0.010 & 0.017 & henry \\
$K_{s m}$ & 1.459 & 0.024 & $\mathrm{Nm}$ \\
$J_{m 1}$ & 0.002 & 0.0036 & $\left(\mathrm{kgm}^{2}\right)$ \\
$b_{m 1}$ & 0.004 & 0.0068 & $\mathrm{Nm} /(\mathrm{rad} / \mathrm{s})$ \\
$k_{s 1}$ & 1.65 & 0.025 & $\mathrm{Nm}$ \\
\hline
\end{tabular}

There are many types of filtering techniques such as low pass filter that has been used in this study. The low pass filter is used to filter out the interference noise from the output of the current sensor.

Figure 18 shows the comparison of the output response for a current sensor with and without using filters. Without a filter, the current sensor has high amplitude interference noise. However, with low pass filter, under the frequency of $5 \mathrm{~Hz}$ the interference noise is reduced and the fluctuations are removed. Thus, this provides a smoother output response.

4.3. Effect on Compensation Torque. A steering torque comparison without and with compensation torque is shown in Figure 19. The results for without compensation torque shows that the steering torque response curve is far away from EPS steering system with different amplitude as shown in Figure 19(a). This happens due to less of derivative reaction torque from the steering wheel motor. Figure 19(b) shows steering torque response with compensation torque.

It is observed that, by adding the additional compensation torque, the steering torque response curve trends fairly close to EPS steering system. Thus, it helps to improve the driver steering feel during manoeuvre and stabilize the system. However, with the wide range adjustment gains of the compensation torque, it could improve the steering torque response.

4.4. Medium Speed Manoeuvre. The experimental steering torque results at medium speed manoeuvre are shown in Figure 20(b) when the steering wheel angle is $\pm 100^{\circ}$ as shown 


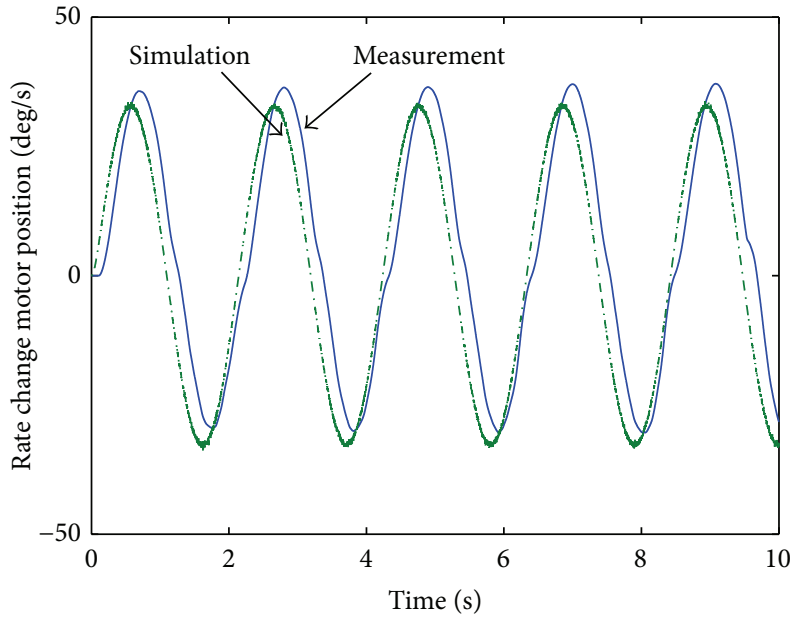

(a) Rate change of motor position

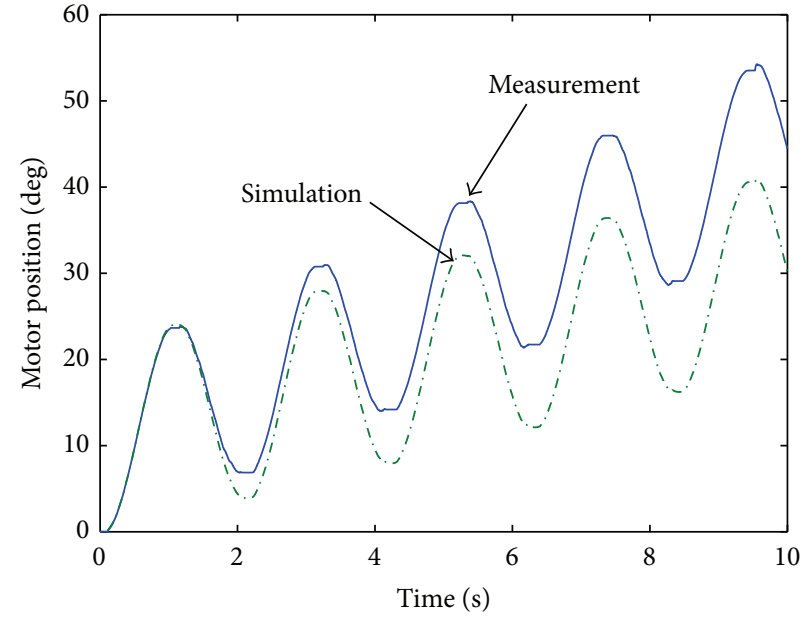

(b) Position of the motor

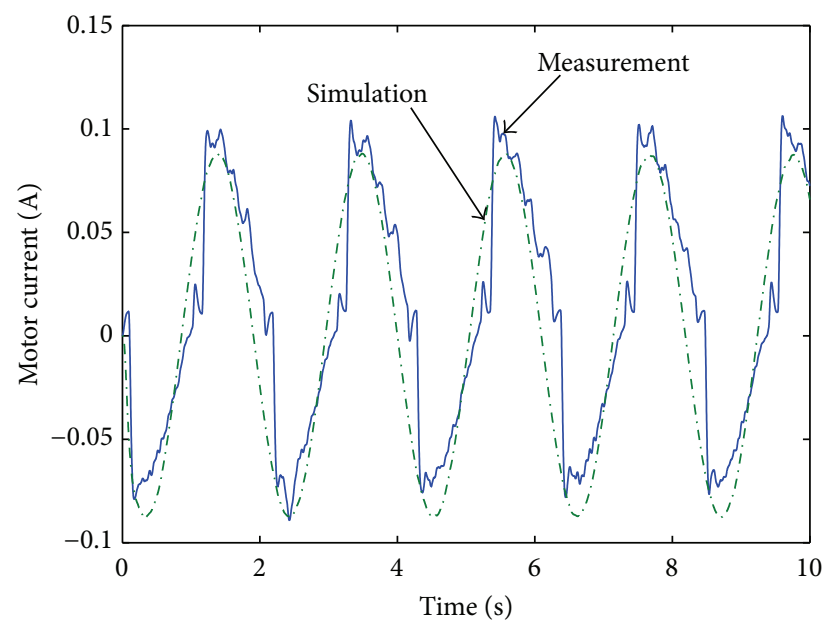

(c) Current of the motor

FIGURE 17: Motor model validation: comparison between simulation and measurement.

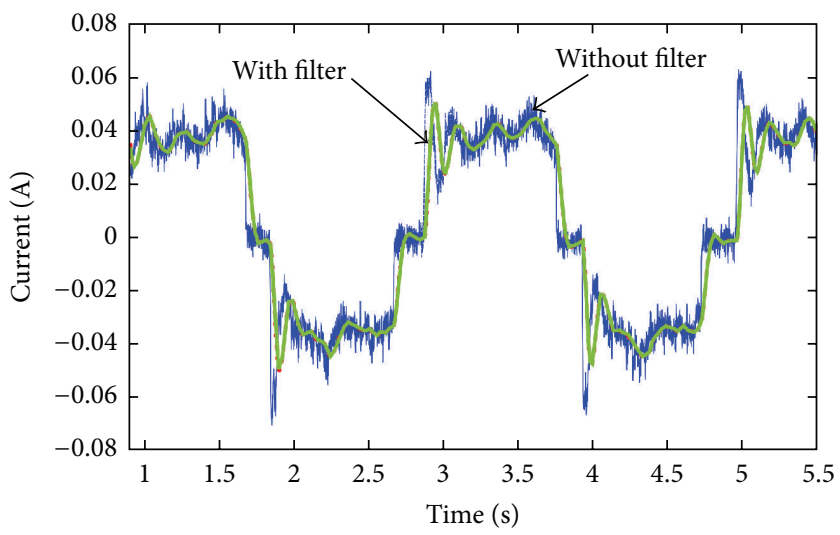

FIGURE 18: Noise filtering using low pass filter.

in Figure 20(a). From the results, the experimental steering torque response is almost identical to the EPS steering system. However, it has small different torque amplitudes. These occur due to the fact that mechanism or friction from the mechanical gearbox motor is not modelled in proposed control algorithm. 


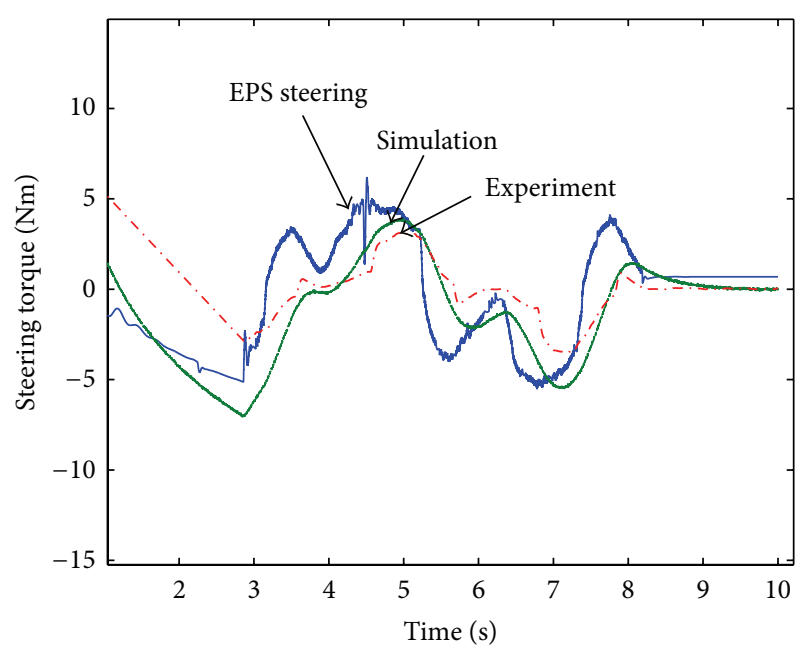

(a) Without compensation torque

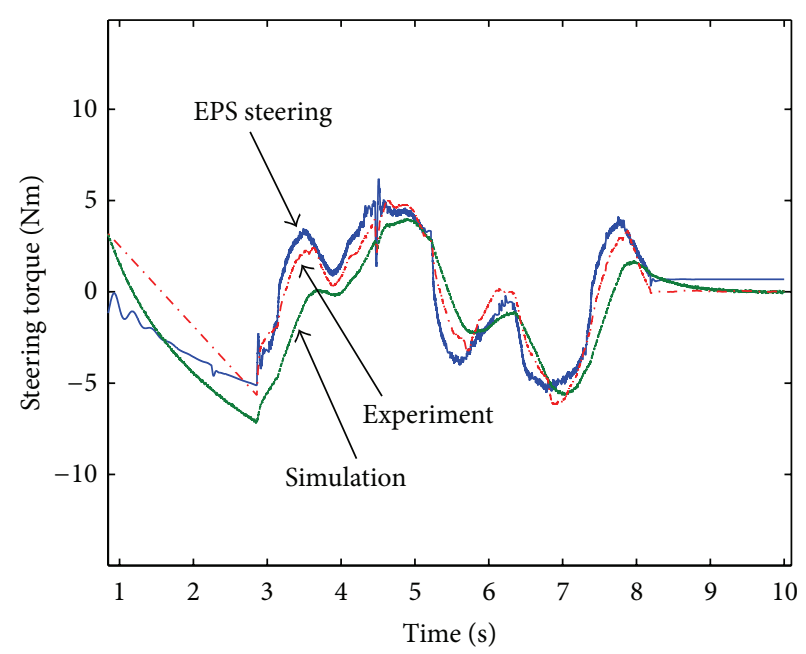

(b) With compensation torque

FIGURE 19: Steering torque influence on compensation torque.

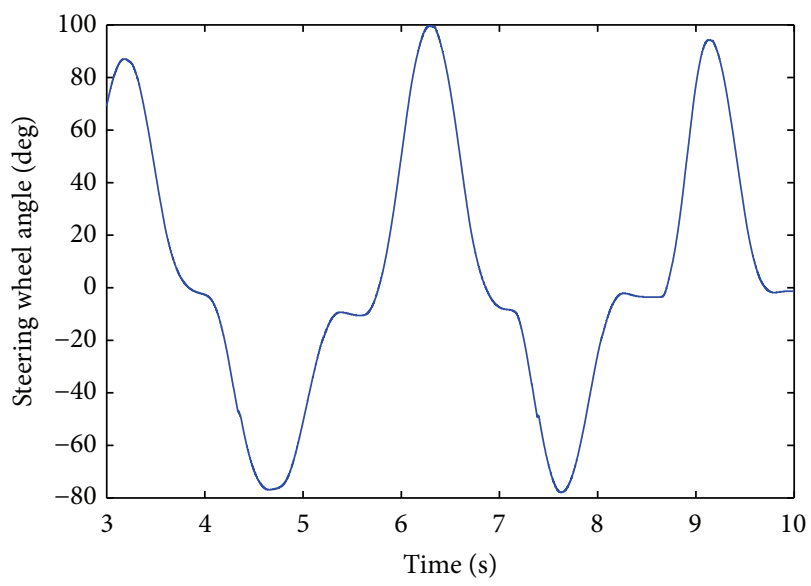

(a) Steering wheel angle at $80 \mathrm{~km} / \mathrm{h}$

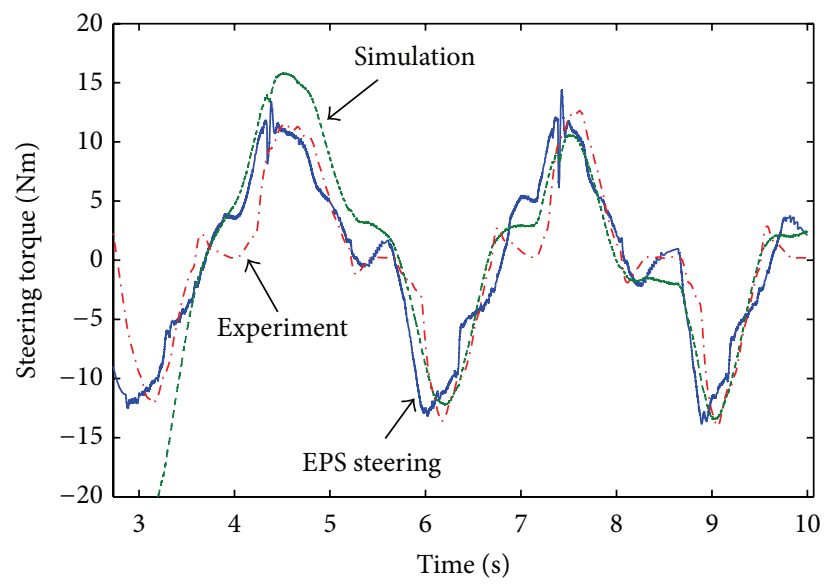

(b) Steering torque estimation at $80 \mathrm{~km} / \mathrm{h}$

FIGURE 20: Steering torque estimation and steering wheel angle response at $80 \mathrm{~km} / \mathrm{h}$.

4.5. High Speed Manoeuvre. At high speed manoeuvre, the input steering wheel angle that is more than $\pm 45^{\circ}$ is very dangerous [12]. Therefore, in this experiment, the input steering wheel angle is less than $\pm 45^{\circ}$ as shown in Figure 21(a). Based on the results shown in Figures 21(b) and 21(c), the experimental steering torque is obtained fairly similar to the EPS steering system. Although the steering wheel angle is at small angles, the influence of vehicle speed cause the steering torque is increased. Moreover, at higher speed, the vehicle has more under steer propensity [9]. This increased the self aligning torque, in proportional high torque at front axle motor. Thus, the driver will sense stiffer on the steering wheel during manoeuvre.

In general, the centering of the steering wheel performance or steering wheel returnability is better when the steering torque gradient is large and the hysteresis is small [9]. Based on this fact, the result is shown in Figure 21(c), whereby the hysteresis of the steering wheel returnability based on experimental result is smaller compared to EPS steering system. In addition, the steering torque gradient is larger than EPS steering torque. Therefore, it is considered that the proposed feedback torque algorithm not only achieved a steering feel but also improved the steering wheel returnability.

4.6. Lower Speed Manoeuvre. The steering torque results at low speed manoeuvre are shown in Figures 22(b) and 22(c) when the input steering wheel is as shown in Figure 22(a). The vehicle cruised at constant speed of $10 \mathrm{~km} / \mathrm{h}$.

The experimental steering torque is almost comparable to EPS torque, but the amplitude is decreases. The torque is decreased due to the fact that the vehicle speed is reduced which is effect on reducing the demand to the total feedback torque. Moreover, the large turning of the steering wheel increases the backlash of the motor which then contributes 


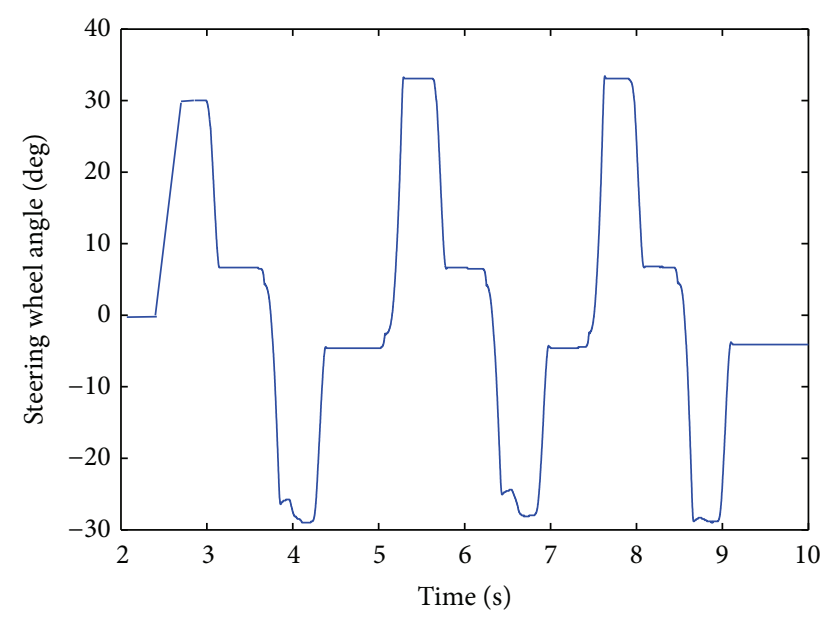

(a) Steering wheel angle at $120 \mathrm{~km} / \mathrm{h}$

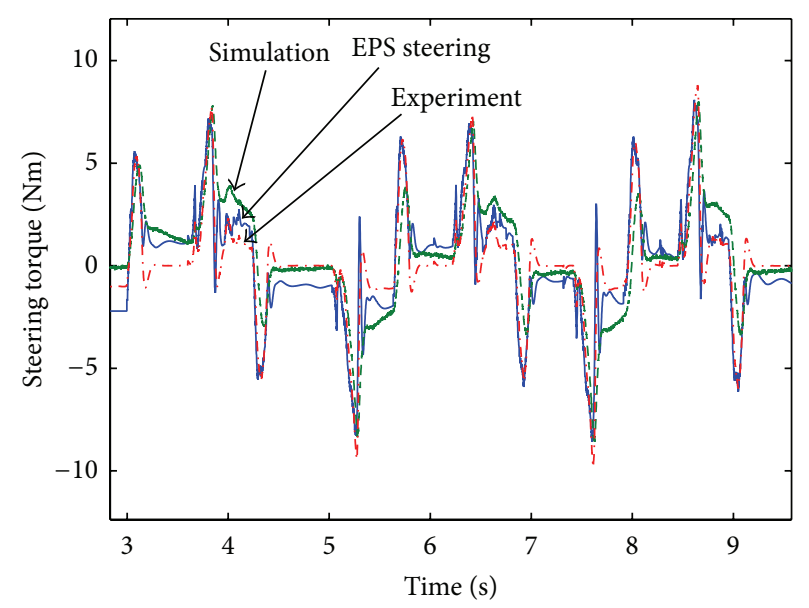

(b) Steering torque estimation at $120 \mathrm{~km} / \mathrm{h}$

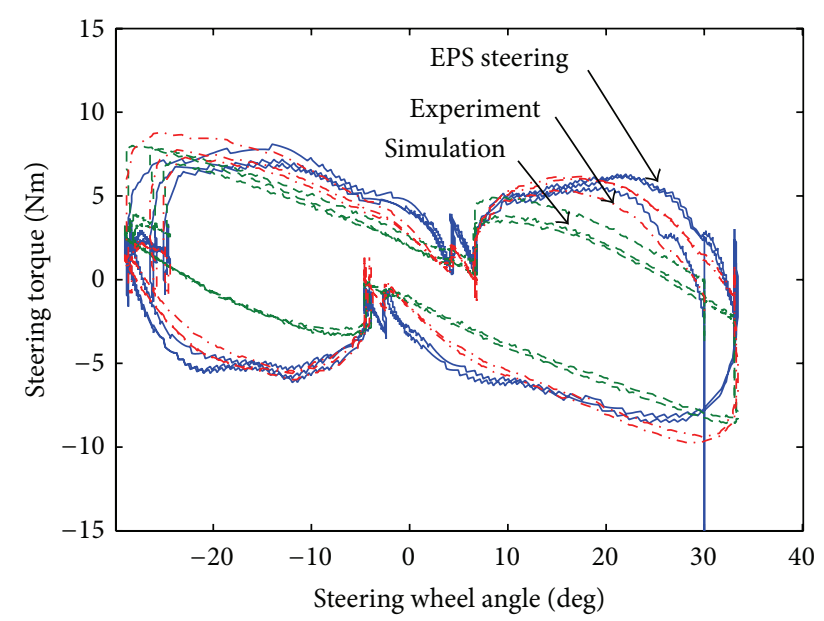

(c) Steering torque estimation against steering wheel angle at $120 \mathrm{~km} / \mathrm{h}$

FIGURE 21: Steering torque estimation response at $120 \mathrm{~km} / \mathrm{h}$.

to the decrease of the motor torque. Thus, driver will sense softer during steering the wheel during maneuver. However, it has small different torque against EPS steering. Wide range adjustment of gains in proposed control algorithm may help improve the steering torque response.

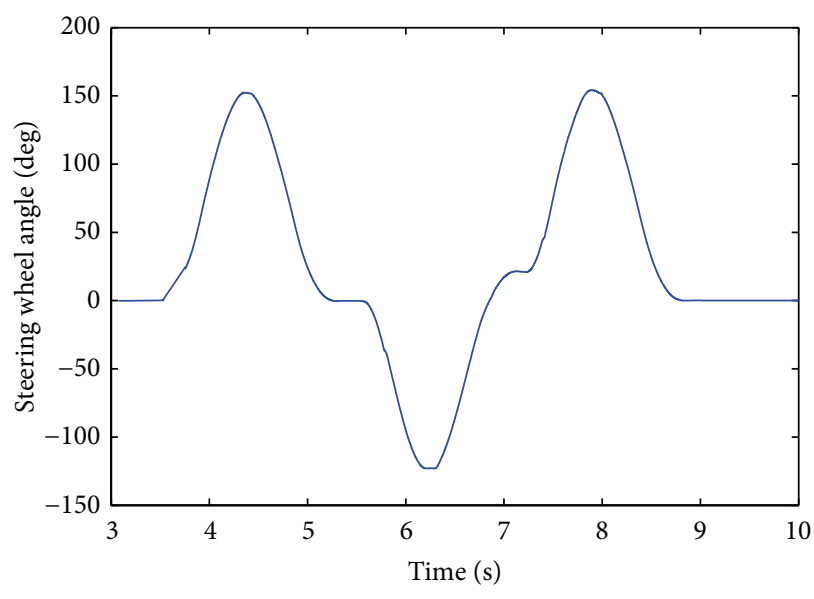

(a) Steering wheel angle

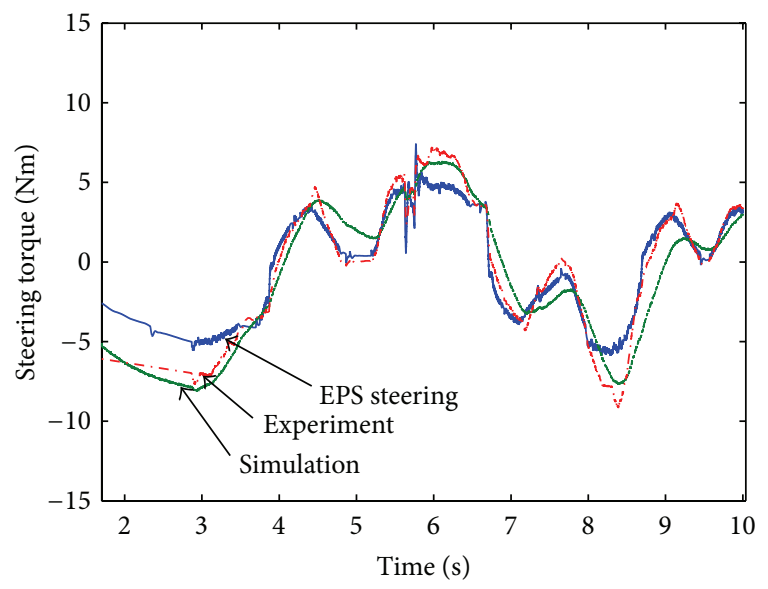

(b) Steering torque estimation at $10 \mathrm{~km} / \mathrm{h}$

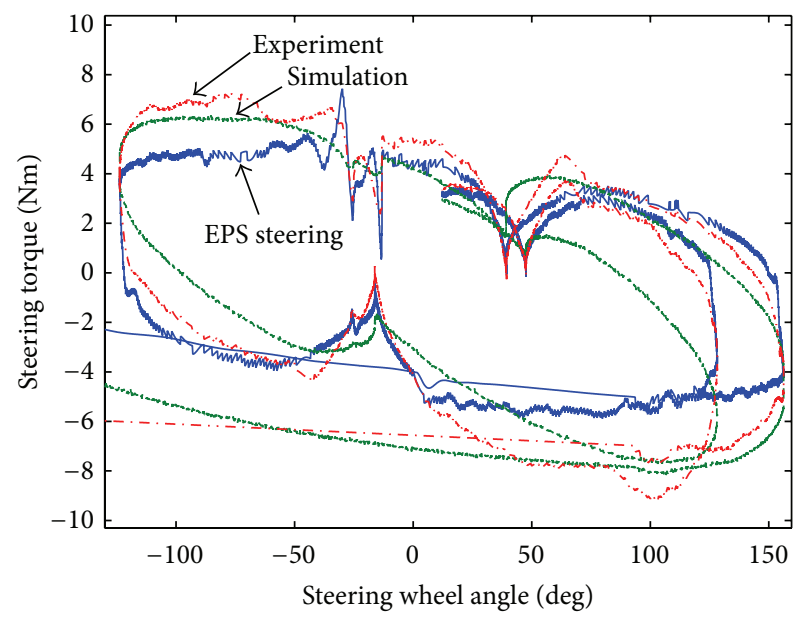

(c) Steering torque estimation against steering wheel angle at $10 \mathrm{~km} / \mathrm{h}$

FIGURE 22: Steering torque estimation response at $10 \mathrm{~km} / \mathrm{h}$.

\section{Conclusion and Future Work}

The proposed force feedback torque estimation and control algorithm have been described. The proposed control algorithm is considered as an effort to generate the feedback 
torque for driver steering feel in the vehicle SBW system. The mathematical model of SBW subsystem consists of steering wheel and front axle systems that are modelled. The effectiveness of the control algorithm is verified through the experimental hardware in the loop (HIL) interfaced with Matlab XPC target toolbox software. According to the experimental results, the proposed control algorithm is able to generate the feedback torque and the driver is able to sense steering feel similar to that obtained in EPS steering system. The LQR controller with gain scheduling based on steering wheel angle and vehicle speed function provides better torque control that allows rejection of the uncertainty torque from a road condition. Furthermore, the steering feel gain is able to increase and lower the steering torque with improved steering stability at high speed and it improved the vehicle manoeuvre at low speed. It is also found that compensation torque is able to improve the feedback torque and to stabilize the system. However, it has small different torque magnitude that occurs due to the backlash of steering wheel motor and uncertainty disturbance of mechanical properties. However, with a wide range adjustment of the gains on the proposed control algorithm, it may improve and provide realistic steering torque for better driver steering feel.

In future work, the proposed control algorithm will be tested in real vehicle in order to have more realistic steering torque for further investigation and analysis.

\section{Conflict of Interests}

The authors declare that there is no conflict of interests regarding the publication of this paper.

\section{Acknowledgments}

This work is fully supported by the Ministry of Higher Education Malaysia and University Technology Malaysia under FRGS (vote: 4F370) and Research University Grant (vote: 00G64). This work is also supported by Proton Holding Berhad.

\section{References}

[1] Y. Yao, "Vehicle steer-by-wire system control," SAE Technical Paper 2006-01-1175, 2006.

[2] E. A. Kumar, D. Dinesh, and N. Kamble, "An overview of active front steering system," International Journal of Scientific \& Engineering Research, vol. 3, no. 6, 2012.

[3] S. M. H. Fahami, H. Zamzuri, S. A. Mazlan, and N. B. Zulkarnain, "The design of vehicle active front steering based on steer by wire system," Advanced Science Letters, vol. 19, no. 1, pp. 6165, 2013.

[4] S. M. H. Fahami, H. Zamzuri, S. A. Mazlan, and S. A. Saruchi, "The variable steering ratio for vehicle steer by wire system using hyperbolic tangent method," Applied Mechanics and Materials, vol. 575, pp. 781-784, 2014.

[5] T. Kaufmann, S. Milsap, B. Murray, and J. Petrowski, "Development experience with steer by wire," in Proceedings of the SAE International Congress and Exhibition, SAE 2001-01-2479, 2001.
[6] S. Amberkare, F. Bolourchi, J. Demerly, and S. Millsap, "A control system methodology for steer by wire systems," SAE Technical Paper 2004-01-1106, 2004.

[7] A. Baviskar, J. R. Wagner, D. M. Dawson, D. Braganza, and P. Setlur, "An adjustable steer-by-wire haptic-interface tracking controller for ground vehicles," IEEE Transactions on Vehicular Technology, vol. 58, no. 2, pp. 546-554, 2009.

[8] M. Segawa, S. Kimura, T. Kada, and S. Nakona, "A study of reactive torque control for steer by wire system," in Proceedings of the International Symposium on Advanced Vehicle Control (AVEC '02), pp. 653-658, Hiroshima, Japan, September 2002.

[9] S. W. Oh, H. C. Chae, S. C. Yun, and C. S. Han, "The design of a controller for the steer-by-wire system," JSME International Journal, Series C: Mechanical Systems, Machine Elements and Manufacturing, vol. 47, no. 3, pp. 896-907, 2004.

[10] C. J. Kim, J. H. Jang, S. K. Oh, J. Y. Lee, and J. K. Hedrick, "Development of a control algorithm for a rack-actuating steerby-wire system using road information feedback," Proceedings of the Institution of Mechanical Engineers Part D: Journal of Automobile Engineering, vol. 222, no. 9, pp. 1559-1571, 2008.

[11] S. Asai, H. Kuroyanagi, and S. Takeuchi, "Development of a steer-by-wire system with force feedback using a disturbance observer," in Proceedings of the SAE World Congress \& Exhibition on Steering \& Suspension Technology, Detroit, Mich, USA, 2004.

[12] T. J. Park, C. S. Han, and S. H. Lee, "Development of the electronic control unit for the rack-actuating steer-by-wire using the hardware-in-the-loop simulation system," Mechatronics, vol. 15, no. 8, pp. 899-918, 2005.

[13] D. Odenhtal, T. Bunte, H. D. Heitzer, and C. Eicker, "How to make steer-by-wire feel like power steering," in Proceedings of the 15th IFAC World Congress, Barcelona, Spain, July 2000.

[14] H. Na, C. Zong, and D. Hu, "Investigations on cornering control algorithm design and road feeling optimization for a steer-by-wire vehicle," in Proceedings of the IEEE International Conference on Mechatronics and Automation (ICMA '09), pp. 3246-3251, Changchun, China, August 2009.

[15] S. Ancha, A. Baviskar, J. R. Wagner, and D. M. Dawson, "Ground vehicle steering systems: modelling, control, and analysis of hydraulic, electric and steer-by-wire configurations," International Journal of Vehicle Design, vol. 44, no. 1-2, pp. 188-208, 2007.

[16] P. Yih and J. C. Gerdes, "Modification of vehicle handling characteristics via steer-by-wire," IEEE Transactions on Control Systems Technology, vol. 13, no. 6, pp. 965-976, 2005.

[17] S. M. H. Fahami, H. Zamzuri, S. A. Mazlan, and M. A. Zakaria, "Modeling and simulation of vehicle steer by wire system," in Proceedings of the IEEE Symposium on Humanities, Science and Engineering Research (SHUSER '12), pp. 765-770, Kuala Lumpur, Malaysia, June 2012.

[18] S. Anwar and L. Chen, "An analytical redundancy-based fault detection and isolation algorithm for a road-wheel control subsystem in a steer-by-wire system," IEEE Transactions on Vehicular Technology, vol. 56, no. 5, pp. 2859-2869, 2007.

[19] M. T. Do, Z. Man, C. Zhang, H. Wang, and F. S. Tay, "Robust sliding mode-based learning control for steer-by-wire systems in modern vehicles," IEEE Transactions on Vehicular Technology, vol. 63, no. 2, pp. 580-590, 2014.

[20] J. Duan, R. Wang, and Y. Yu, "Research on control strategies of steer-by-wire system," in Proceedings of the International Conference on Intelligent Computation Technology and Automation (ICICTA '10), vol. 2, pp. 1122-1125, May 2010. 
[21] B. Zheng and S. Anwar, "Yaw stability control of a steer-by-wire equipped vehicle via active front wheel steering," Mechatronics, vol. 19, no. 6, pp. 799-804, 2009.

[22] S. Sahoo, S. C. Subramanian, and S. Srivastava, "Design and implementation of a controller for navigating an autonomous ground vehicle," in Proceedings of the 2nd International Conference on Power, Control and Embedded Systems (ICPCES '12), pp. 1-6, IEEE, Allahabad, India, December 2012.

[23] T. D. Gillespie, Fundamentals of Vehicle Dynamics, Society of Automotive Engineers, 1992.

[24] M. H. Lee, S. K. Ha, J. Y. Choi, and K. S. Yoon, "Improvement of the steering feel of an electric power steering system by torque map modification," Journal of Mechanical Science and Technology, vol. 19, no. 3, pp. 792-801, 2005.

[25] R. Pastorino, M. A. Naya, J. A. Pérez, and J. Cuadrado, "Geared PM coreless motor modelling for driver's force feedback in steer-by-wire systems," Mechatronics, vol. 21, no. 6, pp. 10431054, 2011.

[26] P. Koehn and M. Eckrich, "Active steering-the BMW approach towards modern steering technology," SAE Technical Paper Series 2004-01-1105, SAE International, 2004. 

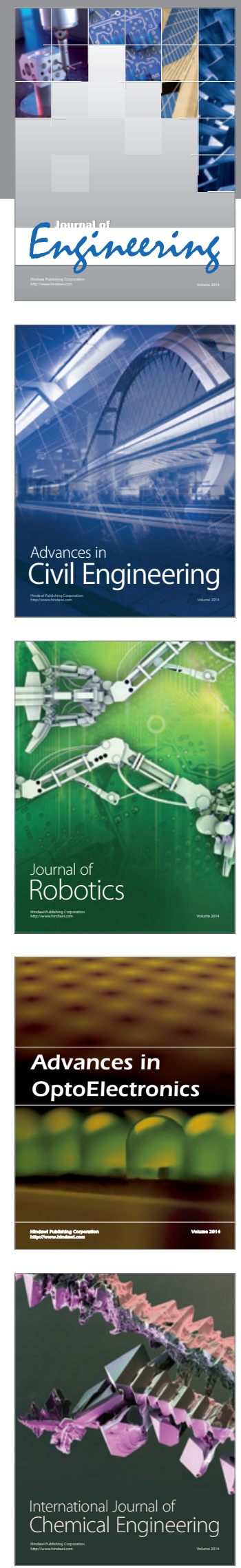

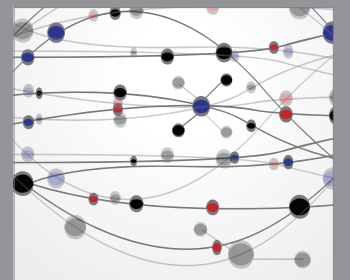

The Scientific World Journal
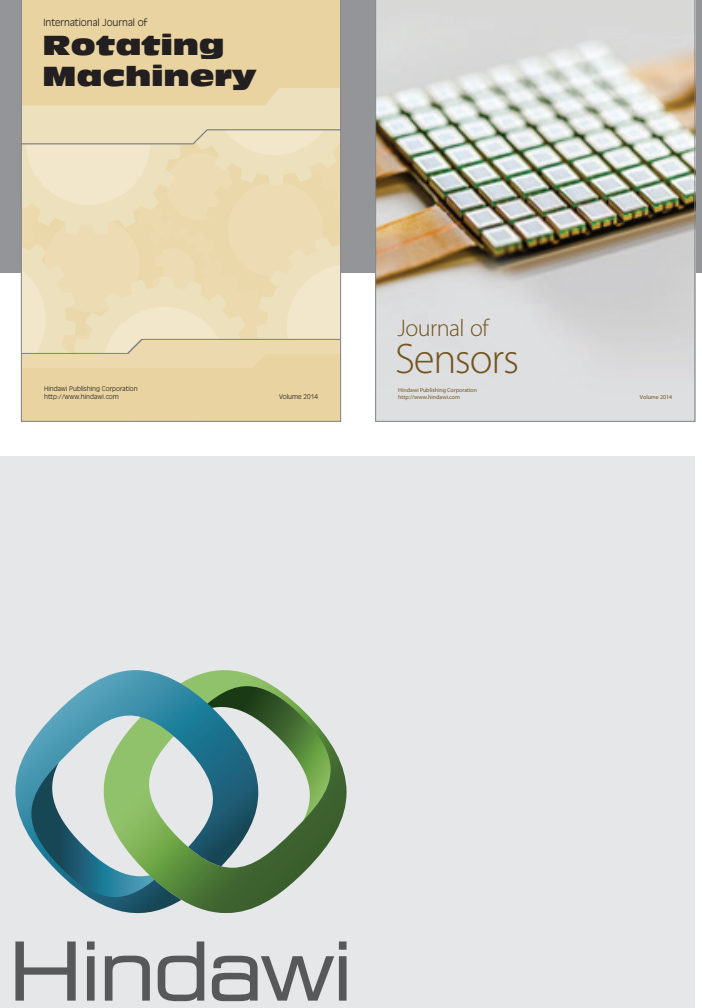

Submit your manuscripts at http://www.hindawi.com
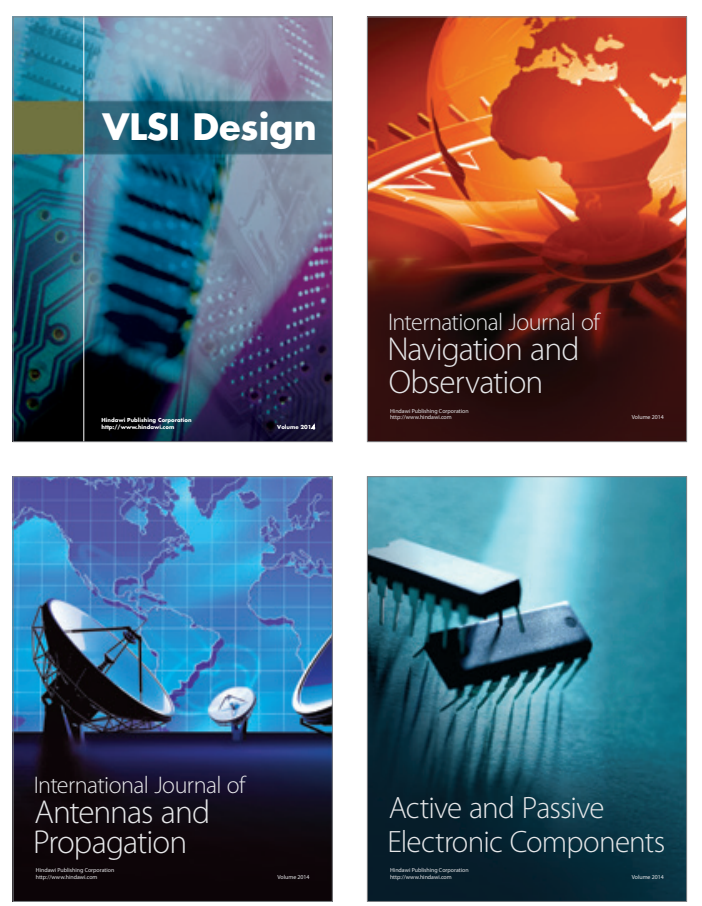
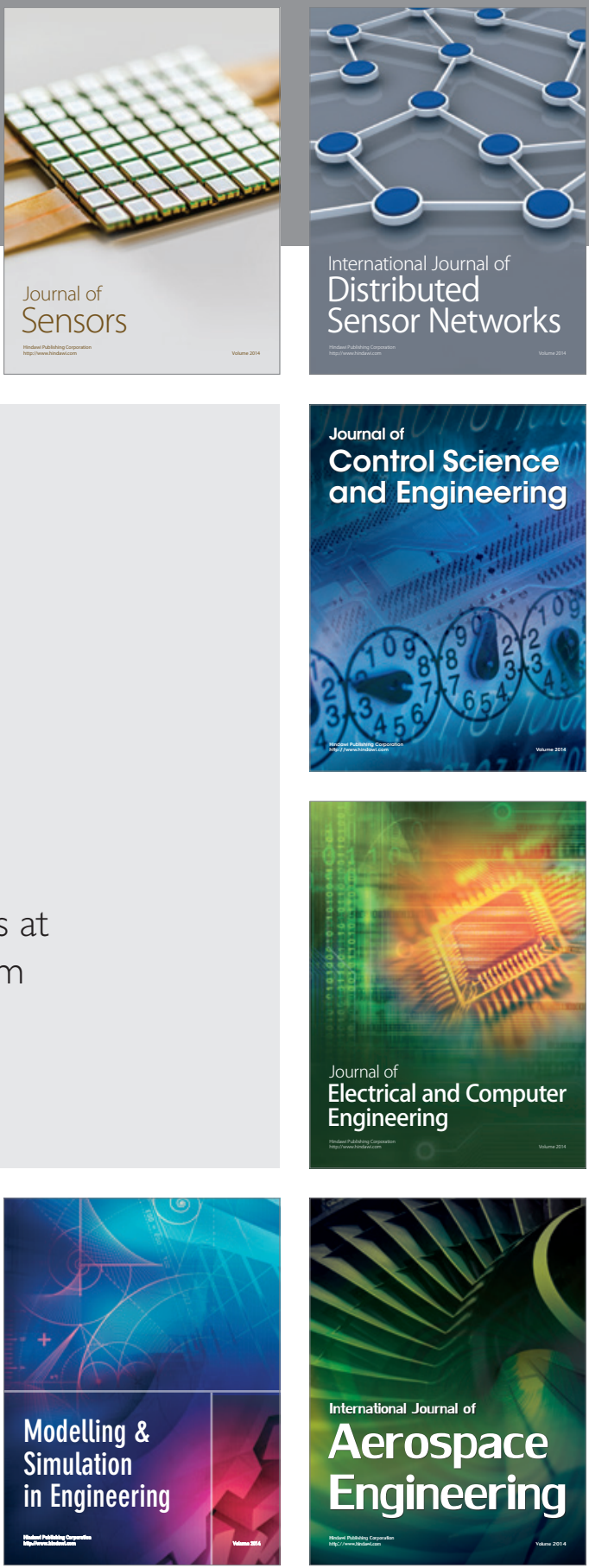

Journal of

Control Science

and Engineering
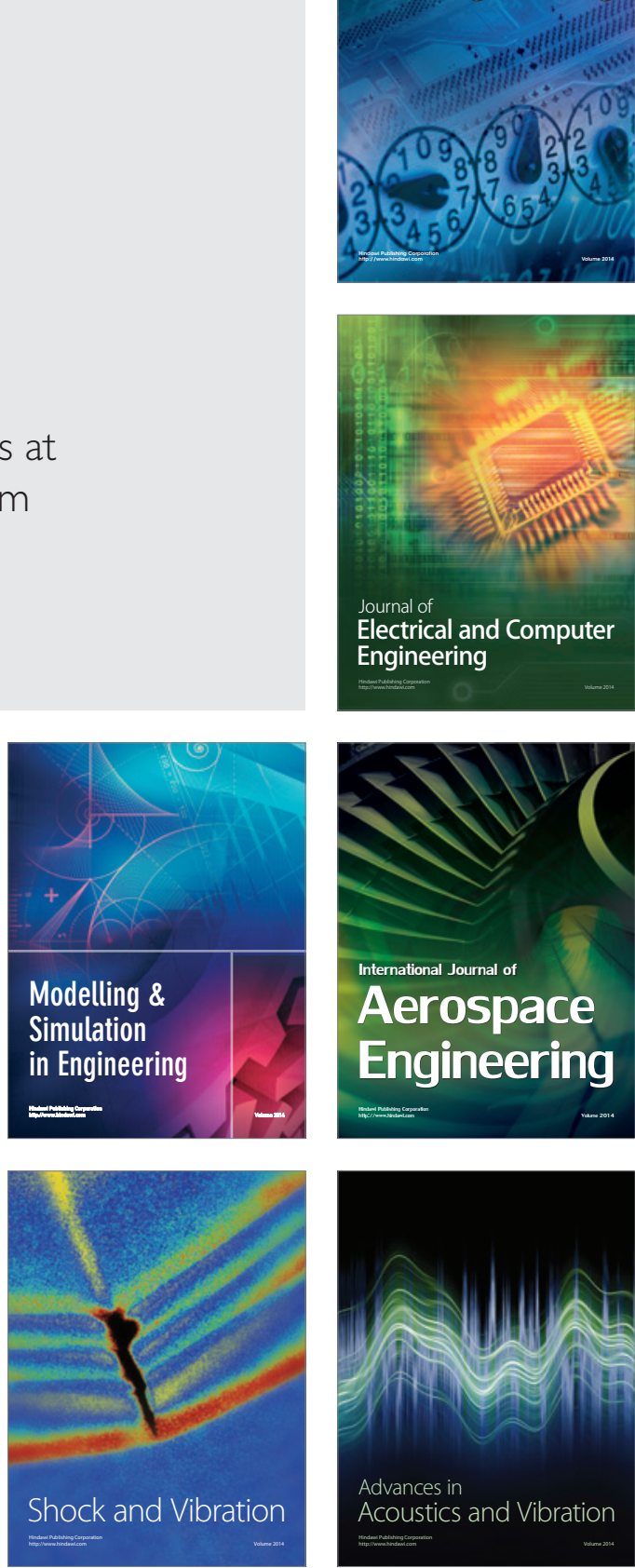